\title{
Nature in Engineering for Monitoring the Oceans: Comparison of the energetic costs of marine animals and AUVs
}

\author{
A.B. Phillips ${ }^{1}$, M. Haroutunian ${ }^{2}$, S.K. Man ${ }^{1}$, A.J. Murphy ${ }^{2}$, S.W. Boyd ${ }^{1}$, J.I.R. Blake ${ }^{1}$ and G. \\ Griffiths $^{3}$ \\ ${ }^{1}$ University of Southampton, Southampton, SO17 1BJ, UK \\ ${ }^{2}$ Newcastle University, Newcastle, NE1 7RU, UK \\ ${ }^{3}$ National Oceanography Centre, University of Southampton Waterfront Campus, Southampton, \\ SO14 3ZH, UK
}

\begin{abstract}
The range of physiological adaptations possessed by marine animals allowing them to successfully operate in the marine environment is a plentiful source of inspiration for the designers of Autonomous Underwater Vehicles. This chapter compares the total energetic cost of straight line swimming for both marine animals and AUVs, using cost of transport (COT) as a comparative metric. COT is a normalised measure of the energetic cost of transporting the animal's or vehicle's mass over a unit distance. It includes non propulsion power requirements as well as considering the energy lost by actuators and mechanical couplings and energy lost in the wake. Comparisons presented in this chapter show that marine animals typically have higher optimum COT than engineered systems of equivalent size. However parallels may be drawn, for example, to increase range both marine animals and AUVs appear to favour reducing non-propulsion power costs and travelling slowly to ensure operating at the minimum COT.
\end{abstract}

Keywords:

Cost of transport, propulsive efficiency, bio-inspired, propulsion system, hotel load, actuator efficiency, power requirements, efficiency, losses, drag, battery technology, metabolic rate 


\title{
Nature in Engineering for Monitoring the Oceans: Comparison of the energetic costs of marine animals and AUVs
}

\author{
A.B. Phillips ${ }^{1}$, M. Haroutunian ${ }^{2}$, S.K. Man ${ }^{1}$, A.J. Murphy ${ }^{2}$, S.W. Boyd ${ }^{1}$, J.I.R. Blake ${ }^{1}$ and G. \\ Griffiths $^{3}$ \\ ${ }^{1}$ University of Southampton, Southampton, SO17 1BJ, UK \\ ${ }^{2}$ Newcastle University, Newcastle, NE1 7RU, UK \\ ${ }^{3}$ National Oceanography Centre, University of Southampton Waterfront Campus, Southampton, \\ SO14 32H, UK
}

\section{Introduction}

Three billion years of evolution have led to numerous methods of marine animal propulsion adapted to movement in three dimensions. The term swimming encompasses the movement of marine mammals and fish, to the motions of cephalopods and medusae, to the slow diurnal vertical migration of zooplankton. Swimming performance is considered a main trait in determining fitness in many aquatic animals, Plaut (2001). Swimming is the only alternative for most aquatic animals to find food, escape predators and successfully reproduce, Videler (1993). Averaged over a period the amount of energy acquired by an individual through feeding must exceed the amount of energy expended by daily activities, growth and reproduction. Based on optimal foraging theory, natural selection should operate to maximise the ratio of energy income to energy expenditure, Townsend and Winfield (1985).

Underwater vehicles operate in the same environment and often have to operate in a similar manner to their natural counterparts. One of the first recorded designs for an underwater vehicle was detailed by William Bourne in 1578, Bourne (1578); Stefoff (2006). 450 years of development has led to a range of vehicles encompassing large nuclear submarines, smaller manned submarines, remotely operated vehicles (ROVs) and autonomous underwater vehicles (AUVs). As complex mechatronic artefacts, there are a myriad of sub-systems within AUVs that could be amenable to bio-inspired design including, among others: sonar waveforms and signal processing based on marine mammal vocalisation, Reijniers and Peremans (2007); bio-inspired swarm intelligence algorithms e.g. for autonomous networking, Dressler (2005); bio-inspired energy sources, e.g. microbial "fuel cells" coupled to artificial muscle, Anderson et al. (2011). However, care needs to be taken when looking for inspiration from biological systems to understand that:

a) The biological system is optimised for the applications of interest, for example many physiological adaptations are due to attracting a mate or other reasons, which may not be the desired outcome.

b) Inspiration should be sought from biological systems that are more efficient than their engineered equivalent.

There appears to be a view in much of the literature that marine animals are energetically more efficient than engineered systems Zhou et al. (2007); Gao et al. (2009). The data presented in this chapter contradicts this argument. In part, this misconception may be due to the outcomes, in isolation, of studies on drag reduction through bio-mimicry e.g. Fish (2006); 
Anthony et al. (2000) or to studies showing high propulsive efficiencies for marine animal and bio-inspired propulsors; e.g. Bose and Lien (1989); Fish (1993); Fish (1996); Anderson et al. (1998). For ships the propulsive efficiency is conventionally defined as the ratio of useful power obtained overcoming resistance at a certain speed to the power delivered to the propeller shaft where torque may be directly measured, as such it incorporates loses in the wake and shaft loses (typically of the order of 1\%), Comstock (1977).

$$
\eta_{P}=\frac{\text { Resistance } \times \text { Velocity }}{\text { Shaft Delivered Power }}
$$

For marine animals the propulsive efficiency is typically inferred from among others: wake studies Tytell and Lauder (2004), Lighthill's elongated body theory, Lighthill (1970); Weihs (1989), strip theories, Bose and Lien (1989) and blade element theories, Blake (1979). As such it only considers losses in the wake.

$$
\eta_{P}=\frac{\text { Resistance } \times \text { Velocity }}{\text { Mechanical Power Delivered }}
$$

Both the above approaches neglect the energy lost converting chemical energy to mechanical energy. By concentrating on one aspect only of the vehicle/animal system, the overall questions of cost of transport and efficiency of energy consumption are rarely completely addressed. Figure 1 illustrates the flow of energy for both an AUV and a fasting, migratory silver eel, starting with potential chemical energy and ending with propulsion power, highlighting energy losses at each stage. This chapter uses a system approach to explain why many AUVs have a lower cost of transport than marine animals of similar size. 

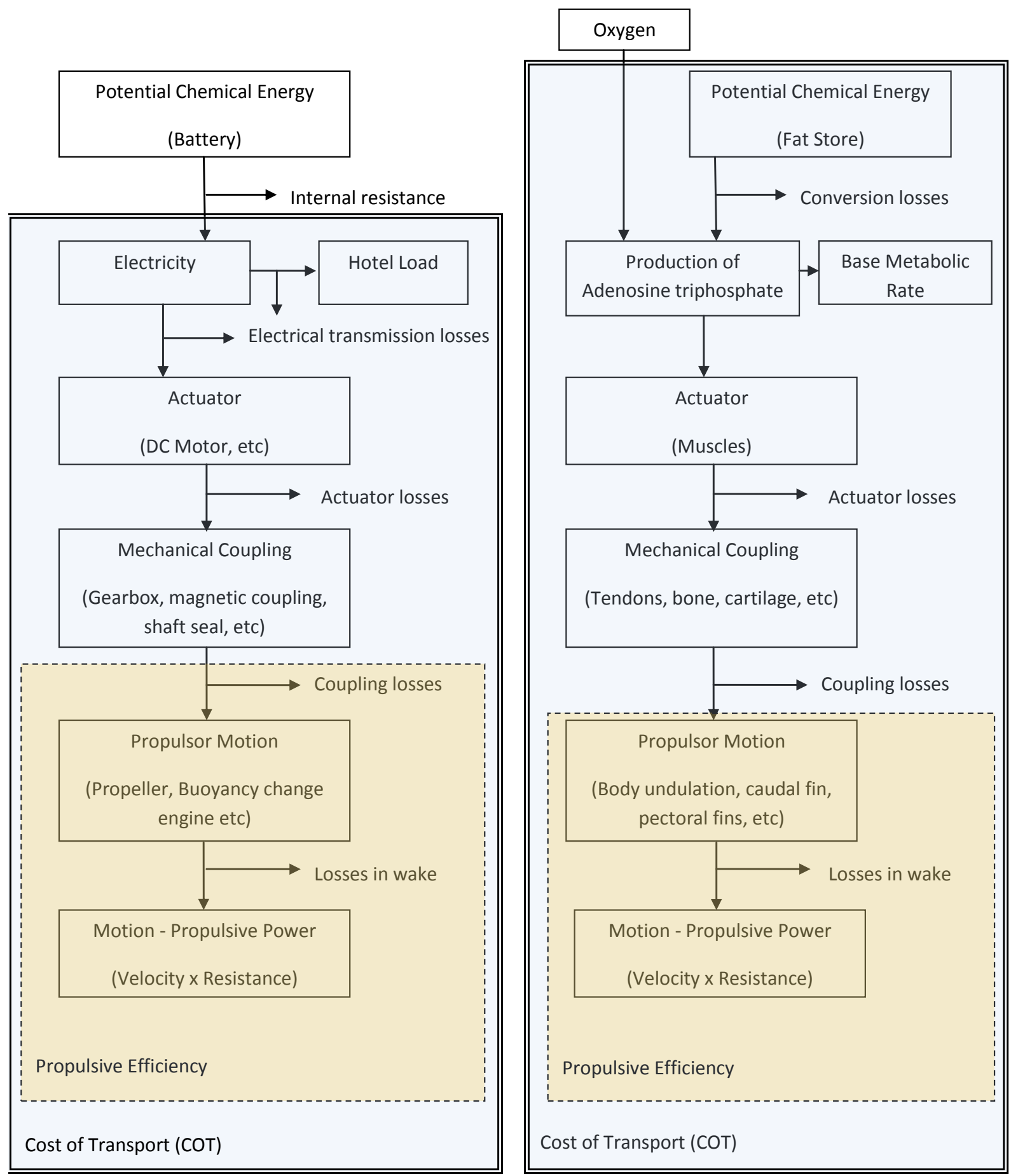

Figure 1 - Diagrammatic comparison of the energy flow for an AUV (left) and a Silver eel (right). Silver eels provide a useful comparison with AUVs since they fast on their $5500 \mathrm{~km}$ migration to their spawning ground, van Ginneken and Maes (2005). 


\section{Cost of Transport}

Cost of transport (COT) is a normalised measure of the energy required to transport the animal's or vehicle's mass over a unit distance. The general formulation of cost of transport is given by:

$$
\text { COT }=\frac{\text { Energy }}{\text { Mass } \times \text { Distance }}=\frac{\text { Power }}{\text { Mass } \times \text { Velocity }}
$$

Cost of transport has units of $\mathrm{J} \mathrm{kg}^{-1} \mathrm{~m}^{-1}$ or equivalently $\mathrm{kJ} \mathrm{kg}^{-1} \mathrm{~km}^{-1}$.

For both AUVs and marine animals, there is a base energetic cost to maintain a number of non-propulsion systems as well as energetic costs of propulsion. For engineered systems the base energetic cost is referred to as the hotel load, and is associated with powering computers, hard drives and sensors.

The energetic costs of propulsion (swimming) are influenced by a variety of environmental factors, propulsion method (swimming modes) and associated efficiency as well as physiological and morphological characteristics of the vehicle (species), Lighthill (1969); Allen et al. (2000); Hammer (1995).

$$
\begin{aligned}
\text { COT } & =\frac{\text { Propulsion Energy }+ \text { Hotel Energy }}{\text { Mass } \times \text { Distance }} \\
& =\frac{\text { Propulsion Power }+ \text { Hotel Power }}{\text { Mass } \times \text { Velocity }}
\end{aligned}
$$

Since conventional AUVs have a finite amount of energy stored onboard, range is inversely proportional to COT. For marine animals, range is a less meaningful parameter since many species do not travel long distances without feeding. For AUVs the cost of transport for each vehicle has been determined based on quoted battery capacity, displaced mass and maximum range available from manufacturer's websites, available literature or personal communications. As such there is an unknown level of uncertainty in the accuracy of the results for COT values deduced from:

$$
\text { COT }=\frac{\text { Total Stored Energy }}{\text { Range } \times \text { Mass }}
$$

In animals, the total energy used can be divided into the following components Smith (1976):

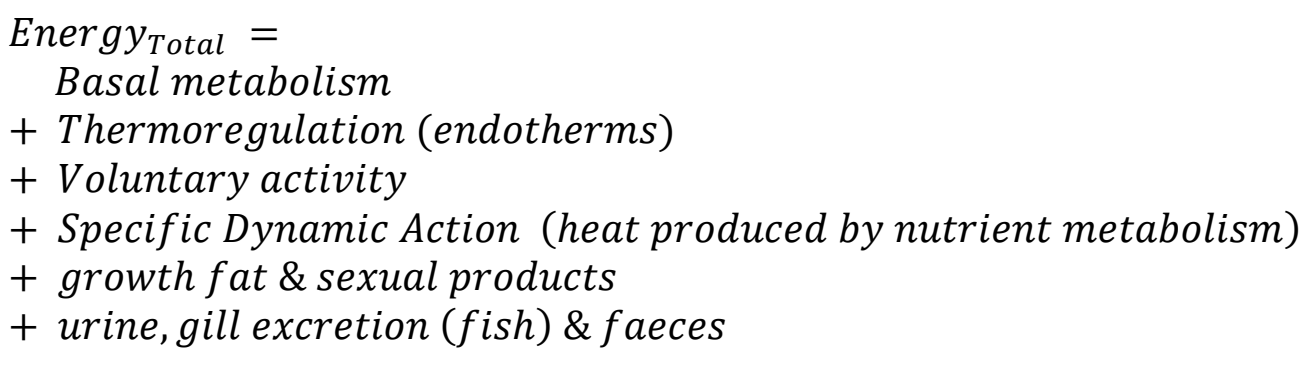


Animals' Basal Metabolism (generally calculated from the Base Metabolic Rate (BMR) for endothermic animals or Standard Metabolic Rate (SMR) for ectothermic animals, referred to herein as BMR for simplicity), which is the equivalent of Hotel Load in AUVs, is the energy used to maintain essential organs and other life support systems and activities through base levels of respiration. For these measurements, animals should be resting, under no stress, and fasting so that energy is not expended for digestion.

Since direct measurement of energy consumption is not possible for marine animals, the amount of oxygen consumption (mg) is measured in order to calculate the energy expenditure. This is based on the fact that oxygen is consumed to burn fat and produce energy. To normalise the data and allow comparison with engineered systems the following calculations have been performed:

$$
\text { Power }_{\text {Total }}(\text { Watts })=\frac{\mathrm{O}_{2} \text { Consumption at } 20^{\circ} \mathrm{C}\left(\frac{\mathrm{mg}}{\mathrm{kg} \times \mathrm{h}}\right) * 13.59 * \operatorname{Mass}(\mathrm{kg})}{3600}
$$

where $13.59 \mathrm{~J} / \mathrm{mg}$ is the $\mathrm{O}_{2}$ Calorific Value Elliott and Davison (1975).

$$
\begin{gathered}
\text { COT }\left(\frac{J}{k g \times m}\right)=\frac{\text { Power }_{\text {Total }}}{\text { Mass } \times \text { Speed }} \\
\text { Base Metabolic Rate }(\text { Watts })=\frac{B M R\left(\frac{m g}{k g \times h}\right) * 13.59 * \text { Mass }(\mathrm{kg})}{3600} \\
\text { Power }_{\text {Propulsion }}=\text { Power }_{\text {Total }}-\text { Base Metabolic Rate }_{\text {BOT }_{\text {Net }}}=\text { COT }_{\text {Total }}-\frac{\text { Base Metabolic Rate }}{\text { Mass } \times \text { Speed }}
\end{gathered}
$$

To allow direct comparison, the temperature of the tests is important. For endotherms, the temperature should be in their neutral thermal zone so energy is not consumed to regulate body temperature, Casellini (2008). For comparison, ectotherms should all be tested at the same temperature (because their BMR changes with temperature); if this is not possible, data gathered from different tests should be normalised to a unique temperature (data gathered from FishBase, Froese and Pauly (2011) are normalised for $\left.20^{\circ} \mathrm{C}\right)$. The normalised metabolic rate is calculated using the temperature coefficient $\left(\mathrm{Q}_{10}\right)$,Winberg (1971); Schmidt-Nielsen (1997):

$$
\mathrm{R}_{2}=\mathrm{R}_{1} \times \mathrm{Q}_{10} \frac{\mathrm{T}_{2}-\mathrm{T}_{1}}{10}
$$

where $R_{1}$ and $R_{2}$ are the rates of a chemical reaction at Temperature one $\left(T_{1}\right)$ and Temperature two $\left(T_{2}\right)$ respectively. Therefore, for our purpose this can be re-written as:

$$
\mathrm{O}_{2} \text { Consumption } \mathrm{T}_{2}=\mathrm{O}_{2} \text { Consumption } \mathrm{T}_{1} \times \mathrm{Q}_{10} \frac{\mathrm{T}_{2}-\mathrm{T}_{1}}{10}
$$

It should be considered that generally animals are tested at the range of speeds at which they would voluntarily swim; therefore the available data does not reflect the complete range of operation of each species. 
Figure 2 illustrates an idealised COT plot. At low speeds the hotel load (BMR), which is invariant to forward speed, dominates driving the COT to infinity at zero forward speed. At high speeds the propulsion power term dominates and the COT rises with increasing speed. Between these two extremes lies an optimum speed which corresponds to a minimum energetic cost per unit distance, $U_{\text {opt }}$. $U_{\text {opt }}$ also corresponds to the speed with the longest associated range. $C O T_{o p t}$ and $U_{\text {opt }}$ are accepted values for comparing energetic costs of marine animals, Videler (1993).

Figure 3 illustrates the significant variations in the COT experienced by many marine animals. Where there is sufficient data available over a large speed range, the mean curves exhibit the expected ' $U$ ' shape. The results show clear variation with respect to, for example, animal size, taxonomy, endothermic or ectothermic. The causes of these variations are discussed in the following sections. One interesting result is that the silver eel has a COT substantially lower than animals of equivalent size, see Figure 3, or Reynolds number, see Figure 4.

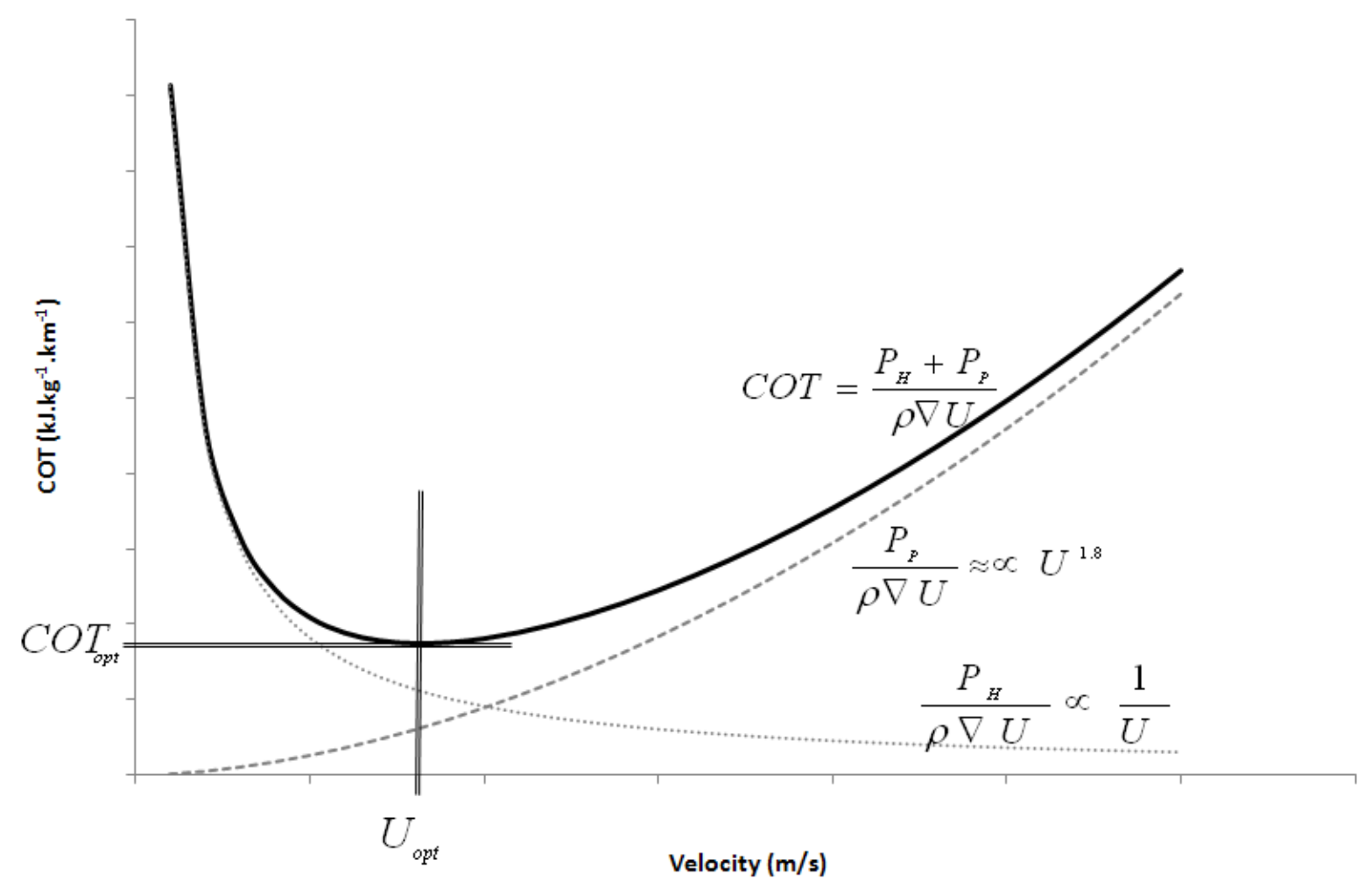

Figure 2 - Idealised cost of transport curve, illustrating the propulsion power $\left(P_{P}\right)$ and hotel power $\left(P_{H}\right)$ 


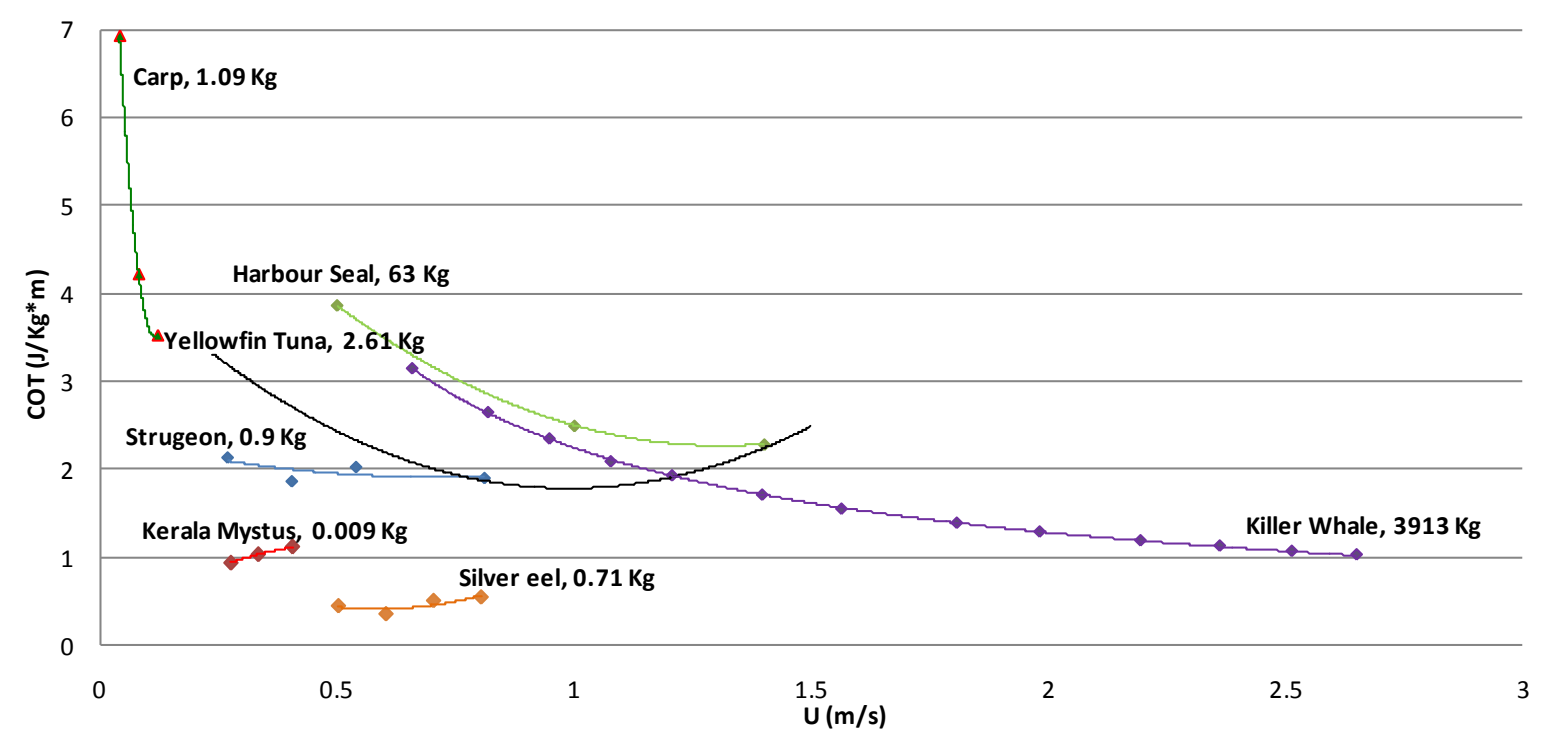

Figure 3 -Total COT of various marine animals Davis et al. (1985); Dewar and Graham (1994); Williams and Noren (2009); Froese and Pauly (2011).

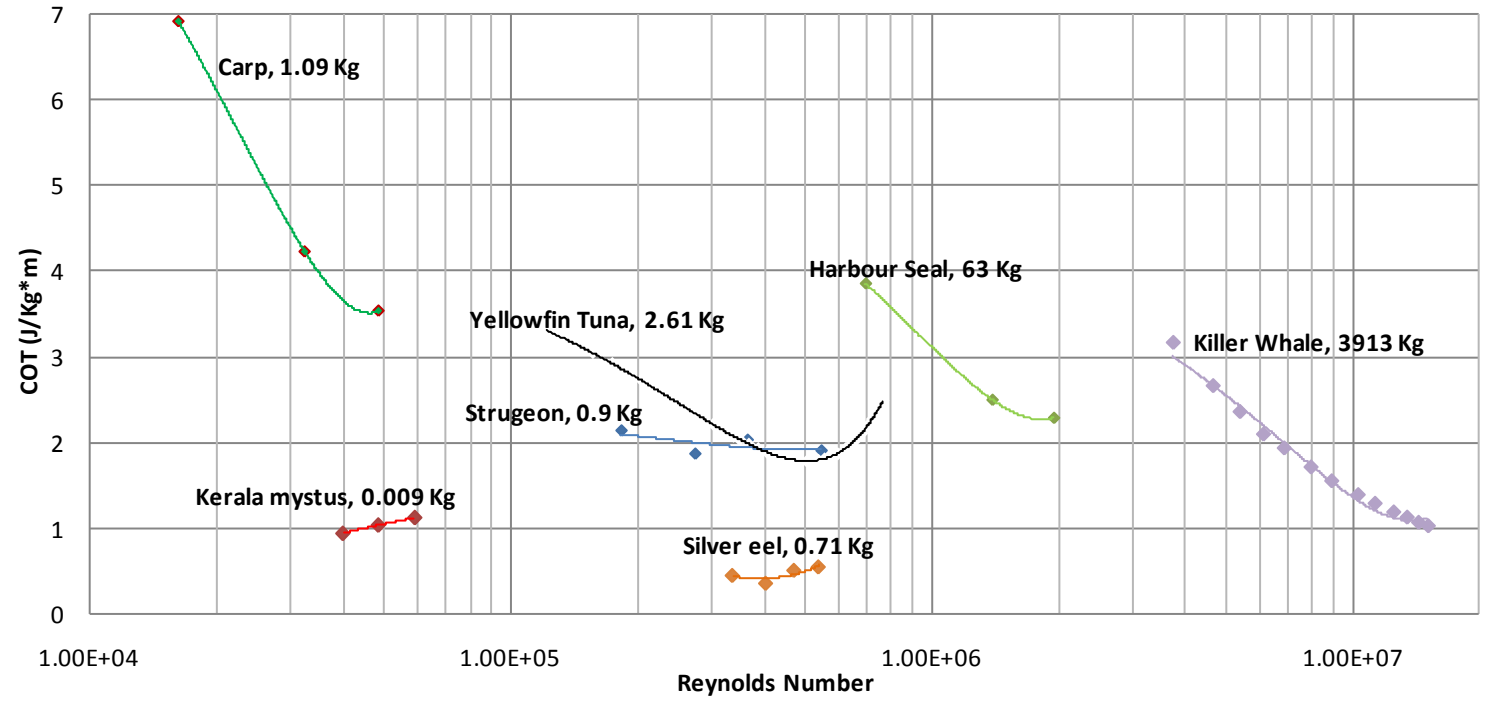

Figure 4 - COT of various animals considering their Reynolds number $(U L / v)$. Data taken from Davis et al. (1985); Dewar and Graham (1994); Williams and Noren (2009); Froese and Pauly (2011).

To illustrate the influence that parameters such as size, speed and hotel load (BMR) have on the cost of transport calculations, the simplified case of a self-propelled prolate spheroid is considered. It is important to note that while this discussion is presented using engineering terminology the concepts discussed are equally applicable to marine animals. The prolate spheroid can be defined using two variables, the polar radius, $b$ (or $L / 2$ ), and the equatorial radius, $a$ (or $D / 2$ ), where $L$ is the polar diameter and $D$ is the equatorial diameter of the spheroid. The angular eccentricity of the spheroid, $e_{a}$, is calculated by taking the arccosine of the ratio of equatorial radius and polar radius.

$$
e_{a}=\arccos (a / b)=\arccos (D / L)
$$

The surface area is given by: 


$$
A=2 \pi\left(\left(\frac{D}{2}\right)^{2}+\frac{D / 2 \times L / 2 \times e_{a}}{\sin e_{a}}\right)
$$

The volume of a prolate spheroid is given by:

$$
\nabla=\frac{1}{6} \pi D^{2} L
$$

Assuming neutral buoyancy in seawater of density, $\rho$, the displaced mass of the system is given by:

$$
\text { Mass }=\rho \frac{1}{6} \pi D^{2} L
$$

An estimate of the propulsive power is given by:

$$
P_{P}=\frac{1}{2 \eta_{P} \eta_{a}} C_{D} \rho A_{W} U^{3}
$$

where $C_{D}$ is the drag coefficient, $A_{w}$ is the wetted surface area, $\eta_{p}$ is the propulsive efficiency, which is taken as the ratio of the effective power delivered by the propulsor compared to the power delivered to the propulsor by the 'shaft'. It accounts for hull efficiency, propulsor efficiency and the influence on the propulsor of operating behind a vessel. $\eta_{a}$ is the actuator efficiency and represents the efficiency of transferring electrical energy into mechanical energy and $U$ is the spheroid's velocity. At first glance it appears that the propulsion power requirement increases with velocity cubed. In practice both propulsive efficiency and drag coefficient are Reynolds number, and hence velocity, dependent. For streamlined bodies experiencing laminar flow the drag coefficient is proportional to $R e^{-0.5}$, and $R e^{-0.2}$ for turbulent flows, Alexander (2005). Thus for low Reynolds numbers $(R e<100,000)$ the propulsive power is proportional to velocity ${ }^{2.5}$ and velocity ${ }^{2.8}$ at turbulent Reynolds numbers.

The total drag acting on a submerged body away from the free surface is a combination of skin friction drag and pressure drag. For ships it is normal to use the ITTC'57 correlation line to estimate the skin friction coefficient for a towed body, SNAME (1957).

$$
C_{f}=\frac{0.075}{\left(\log _{10}(R e)-2\right)^{2}}
$$

This formulation includes the influence of Reynolds number $(\operatorname{Re}=U L / v)$ which indicates the local flow regime, laminar flow leads to a rapid increase in the skin friction coefficient below a Reynolds number of 100,000 . In order to estimate the pressure drag component it is normal practice for naval architects to use a form factor $(1+k)$ as a multiplier on the frictional drag coefficient to estimate the total drag coefficient, Comstock (1977), thus:

$$
C_{D_{h}}=C_{f}(1+k)
$$

For a streamlined body the form factor can be estimated from Hoerner (1965):

$$
(1+k)=1+1.5\left(\frac{D}{L}\right)^{3 / 2}+7\left(\frac{D}{L}\right)^{3}
$$

Such an approach provides a fair estimate of the naked hull resistance of typical torpedo style AUVs, Phillips et al. (2007). To make allowance for the drag of control surfaces and other appendages the bare hull drag is increased by $20 \%$. The total COT may thus be estimated from: 


$$
C O T=\frac{1.2 /\left(2 \eta_{p} \eta_{a}\right) \frac{0.075}{\left(\log _{10}(U L / v)-2\right)^{2}}\left[1+1.5\left(\frac{D}{L}\right)^{3 / 2}+7\left(\frac{D}{L}\right)^{3}\right] \rho 2 \pi\left((D / 2)^{2}+\frac{D L e a}{4 \sin e_{a}}\right) U^{3}+P_{H}}{\rho \frac{1}{6} \pi D^{2} L \times U}
$$

where $e_{a}=\arccos (D / L)$

Hence,

$$
C O T=f\left(L, \frac{L}{D}, U, P_{H}, \eta_{p}, \eta_{a}, v, \rho\right)
$$

The density and kinematic viscosity are properties of the surrounding fluid rather than the AUV or marine animal. The influence of the remaining six parameters is illustrated in Figure 5 .

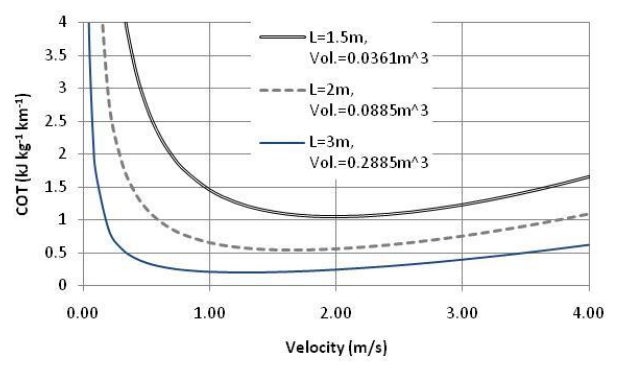

(a) Influence of vehicle size

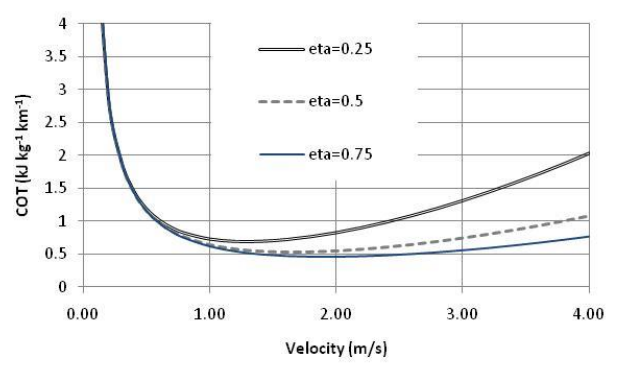

(c) Influence of total propulsion system efficiency $\eta_{p} \eta_{a}$

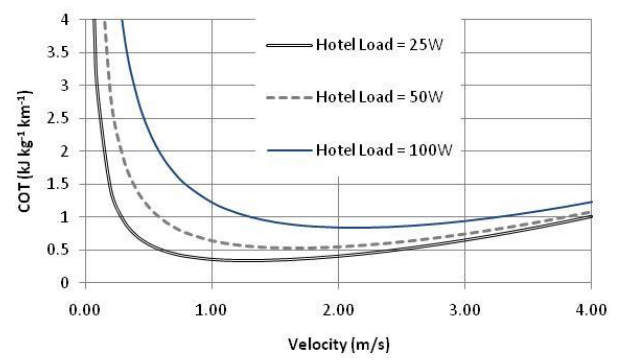

(b) Influence of hotel Load

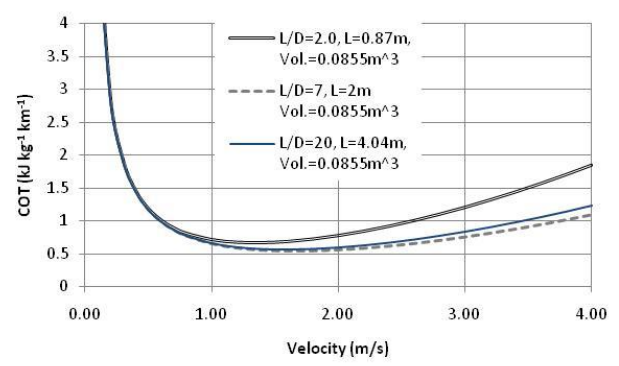

(d) Influence of length/diameter ratio

Figure 5 - Influence of various parameters on the Cost Of Transport (COT). Unless otherwise identified, calculations are based on $L=2 m, P_{H}=50 W, \eta_{p} \eta_{a}=0.5, L / D=7, \rho=1025 \mathrm{~kg} / \mathrm{m}^{3}$ and $v=1.19 \times 10^{-6} \mathrm{~m}^{2} \mathrm{~s}^{-1}$ 
Since drag is proportional to volume to the power two thirds, increasing vehicle size reduces the propulsion power requirements per unit mass and hence the cost of transport drops, and so does the associated $U_{\text {opt }}$. At low speeds $\left(U<U_{\text {opt }}\right)$ the COT is highly sensitive to hotel load. The magnitude of $C O T_{\text {opt }}$ is also highly sensitive to hotel load. As the hotel load tends to zero so does the magnitude of $C O T_{\text {opt }}$. A hotel load of zero will result in $U_{o p t}=0$, clearly this is not a practical transit speed, thus the operator will have to make a compromise between selecting a suitable speed to transit between two points and the energy cost associated with that speed.

Increases in propulsion system efficiency significantly reduces the COT at higher speeds $\left(U>U_{\text {opt }}\right.$ ), where propulsion power dominates, at speeds less than $U_{\text {opt }}$ the propulsion system efficiency has limited influence on COT.

Length/Diameter ratio influences the volumetric drag of the vehicle; at low $L / D$ ratio the frictional drag component is small while the pressure drag component is large. At high $L / D$ ratios the frictional drag is large while the pressure drag is small. Using the above formulations the minimum drag is obtained at $L / D$ ratio of 6.36 . Departures from this value lead to higher drag coefficients which lead to increases in COT at high speeds, $U>U_{\text {opt }}$. In fish, body shape (fineness ratio) has been shown to be an important factor for energy reducing strategies for fish operating at speeds higher than $U_{\text {opt }}$, Ohlberger et al. (2006).

\subsection{Hotel Power / Metabolic Rate}

The non-propulsion power requirements dominate the cost of transport calculation at speeds below $U_{\text {opt }}$ and have a significant impact on the maximum range of an AUV. To understand the biological equivalent in an example class of marine animals, the Kleiber relationship, Kleiber (1932) is typically used by biologists to predict the basal metabolic rate of marine mammals:

$$
B M R=3.39 \operatorname{mass}^{0.75}
$$

BMR in a resting, thermoneutral, post-absorptive, non-growing individual is often assumed to be the lowest stable metabolic rate of an individual, Boyd (2002). For marine mammals this may not be comparable with the AUV hotel load since thermoregulation also needs to be considered. An alternative metric is the field metabolic rate (FMR); this is the metabolic rate of free ranging animals in the field but it may incorporate some level of swimming activity. Boyd (2002) notes that for larger animals, the FMR tends to the BMR predicted by the Kleiber relationship, suggesting that for larger marine mammals thermoregulation costs less energy per unit mass. It is worth noting that unlike man-made actuators, biological muscles will consume energy at rest, which contributes to the metabolic rate of the animals. Typical values for humans show that muscle consumes $54.4 \mathrm{~kJ} / \mathrm{kg} /$ day at rest, which is significantly higher than bone $(9.6 \mathrm{~kJ} / \mathrm{kg} / \mathrm{day})$ and adipose tissue $(18.8 \mathrm{~kJ} / \mathrm{kg} / \mathrm{day})$. However, it is much lower than the remainder of the internal organs (or high metabolic residual mass) which consume $225.9 \mathrm{~kJ} / \mathrm{kg} /$ day, Heymsfield et al. (2002).

Figure 6 compares the field metabolic rate of marine mammals (data collated from various sources by Boyd (2002)) with the hotel load of AUVs, note the log, log scale. Typically marine mammals have a power requirement not associated with propulsion of one order of magnitude greater than AUVs of similar mass. Gliders and long-range vehicles with very low hotel loads have non-propulsion power requirements of two or three orders of magnitude smaller than marine mammals of similar size. These long range vehicles have sacrificed 
linear or area coverage rate and limited the choice of sensors to low power devices in order to minimise the hotel load. It is also interesting to note the lower BMR of various eel species compared to salmonoid fish.

The relationship between field metabolic rate and marine mammal mass has a good correlation $\left(\mathrm{R}^{2}=0.8609\right)$. However, the AUVs (excluding long range vehicles) demonstrate significant scatter $\left(\mathrm{R}^{2}=0.4043\right)$. This may be attributed to the range of available instruments each vehicle may be fitted with in order to complete their mission, for example a fluxgate heading sensor e.g. PNI TCM5, PNI (2011), (0.01W) or a fibre optic gyro e.g. IXSEA PHINS, IXSEA (2011), Inertial Navigation System (INS) (15W) or a Persistor CF2 $(<0.2 \mathrm{~W})$, Persistor Instruments Inc (2010), may be the controller for vehicles from tens to hundreds of kilos in mass.

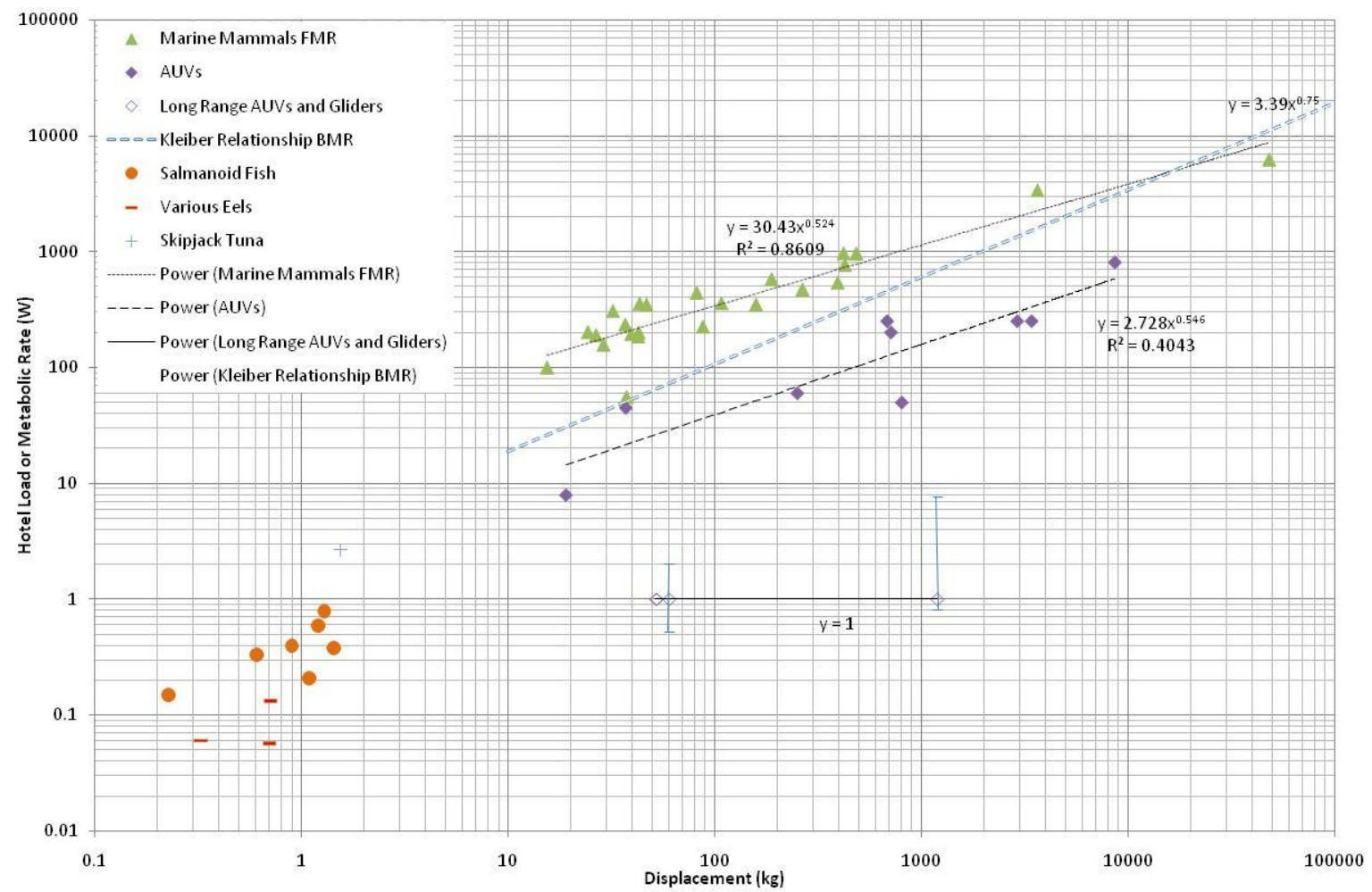

Figure 6 - Comparison of AUV $(n=12)$ hotel load, marine mammal $(n=25)$ field metabolic rate and fish BMR. For AUVs the mass quoted is the displaced mass corresponding to the outer hull volume, and thus includes the mass of water in free flooding spaces in the hull Data for marine mammals collated from various sources by Boyd, Boyd (2002). Fish data calculated from $\mathrm{O}_{2}$ consumption values from Froese and Pauly (2011). Example error bars are presented for the Seaglider (ca. 60kg) and AutosubLR (ca.1000kg) vehicles.

\subsection{Propulsion Power}

Propulsion power costs make a significant contribution to the COT at speeds greater than $U_{\text {opt }}$. Energy lost by propulsion system inefficiencies can account for a large portion of energy expenditure in an AUV. Along with under-predicting the drag and over-predicting the mass of batteries that may be carried, over-predicting the propulsion system efficiency is a common cause of an AUV being unable to achieve the design range at the desired speed, 
Stevenson et al. (2007). There are losses in every stage of the propulsion system (see Figure 1) from power source to propeller. Some of these losses are caused by inefficiency in energy conversion, from chemical energy to electricity (e.g. internal resistance in batteries), from electricity to mechanical energy, shaft losses and finally from mechanical energy in the propulsor to those in the fluid. Other losses come from powering support systems such as motor controller and power regulators.

At a fundamental level the power is required to overcome the hydrodynamic drag experienced by the animal or vehicle. Good quality drag data for marine animals and AUVs is limited. However, length/diameter ratios are more widely available and give a good indication of the level of streamlining of the hull (body) which in turn is indicative of the drag; see Figure 7, where "diameter" for marine animals is the largest cross sectional depth or height measured along the body. All but one of the marine animals considered have length/diameter (L/D) ratios in the range of 3 to 7.5; although the sample is small compared to the total number of species and the species for which data is available tend to have good swimming performance. The exception is the silver eel with a length diameter ratio of 16.6. The AUVs exhibit greater variation, with about $80 \%$ of them having L/D ratios larger than 3; those with an L/D less than 3 are generally box frame AUVs, which are more ROV-like in their appearance and operation.

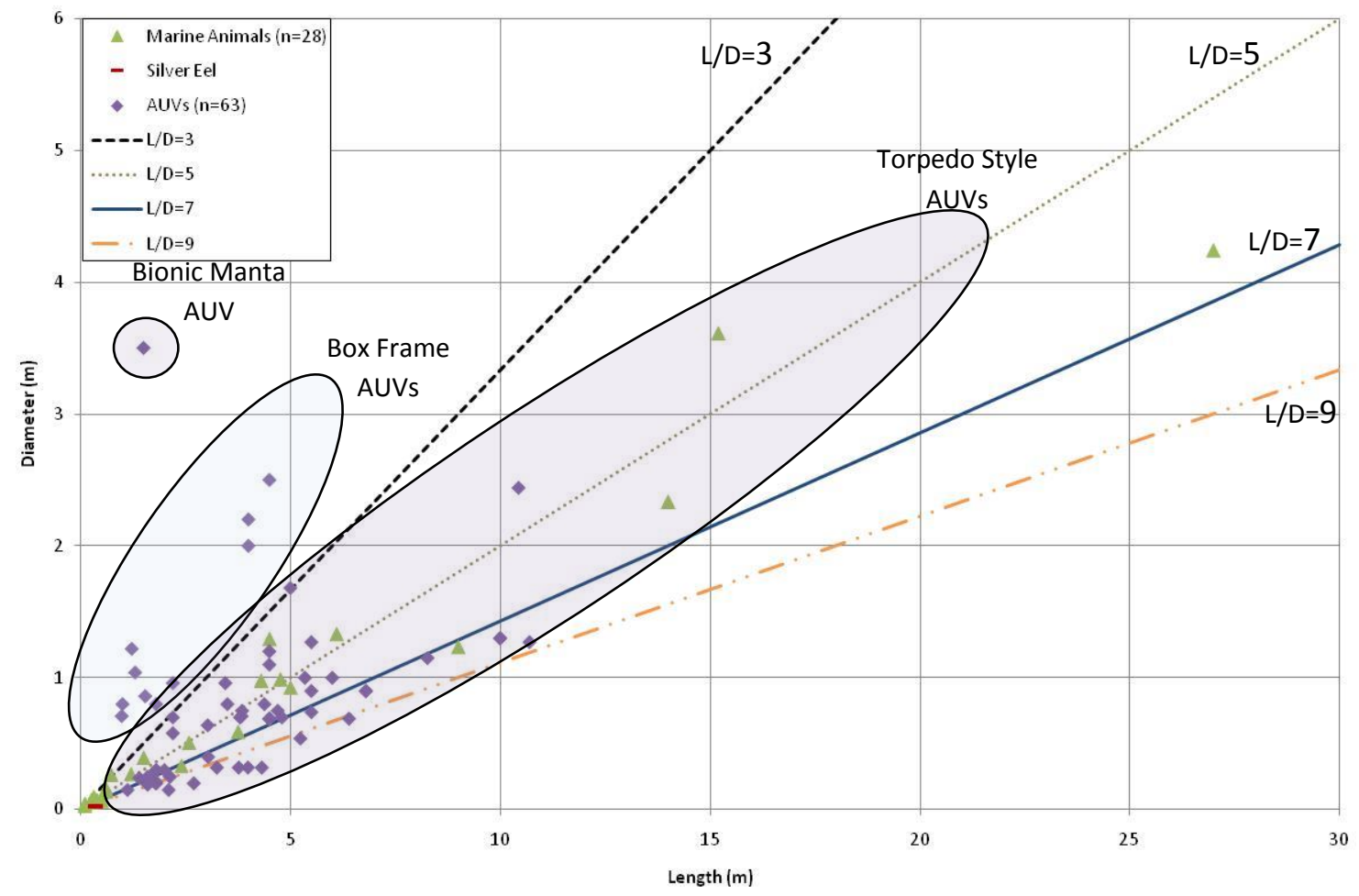

Figure 7 - Comparisons of diameter (or widest lateral dimension) versus length for a selection of AUVs $(n=28)$ and marine animals $(n=28)$. The shaded areas highlight the type of vehicle configuration.

Returning to equations (2.11 through 2.20) an estimate of the towed naked hull drag of a $3.5 \mathrm{~m}^{3}$ volume prolate spheroid travelling at $2 \mathrm{~m} / \mathrm{s}$ has been performed; the results are shown in Figure 8 . While the drag rises rapidly at length diameter ratios of below 3 due to separation at the stern of the vehicle increasing the pressure drag component, the drag only varies by less than $20 \%$ for L/D ratios of between 3 and 12 and by less than $5 \%$ for L/D ratios of between 4 
and 12 . Obviously naked hull drag is not the complete story, control surfaces or fins and other protuberances such as aerials can add substantially to the total drag, Phillips et al. (2010).

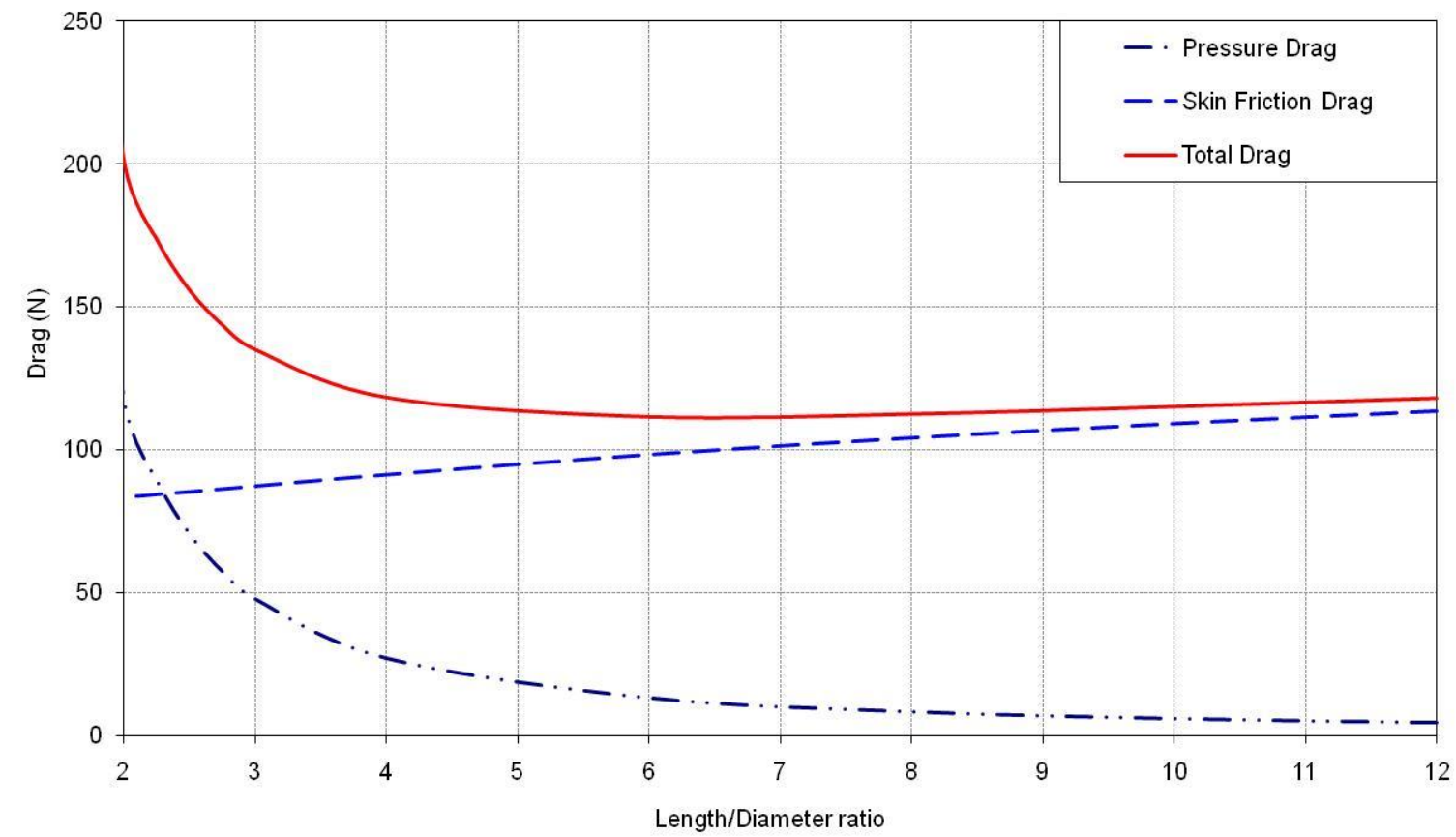

Figure 8 - Influence of length/diameter ratio on a $3.5 \mathrm{~m}^{3}$ streamlined hull travelling at $2 \mathrm{~m} / \mathrm{s}$.

Numerous authors have quoted high propulsive efficiencies $\left(\eta_{D}\right)$ for marine animals using carangiform and thunniform type propulsion (high speed long-distance swimmers where virtually all movement is in the caudal fin). For example, the propulsive efficiencies of pseudo killer whales at 0.9, Fish (1996), bottlenose dolphins at 0.81, Fish (1993), and fin whale at 0.85, Bose and Lien (1989) are high compared with those of a typical propeller (Wageningen B5-75) open water efficiency of 0.5 to 0.7, Carlton (2007). Anderson et al. (1998) and Read et al. (2003) examined the thrust produced by a NACA0012 foil $(60 \mathrm{~cm}$ by $10 \mathrm{~cm}$ with end plates) heaving and pitching in a manner similar to thunniform propulsion at a range of Strouhal numbers and maximum foil incidence angles. Anderson et al. (1998) measured a peak propulsive efficiency of 0.87 with proper selection of Strouhal number, angle of attack, heave amplitude ratio and phasing of the heave and pitch motions. However, Read et al. (2003) were unable to replicate these results, achieving a lower maximum efficiency of 0.715 . Lower aspect ratio oscillating foils experience significant end effects due to the presence of tip vortices, which reduce both thrust production and efficiency compared to the infinite foil case, Dong (2005).

Other swimming approaches have less impressive propulsive efficiencies: the American eel (Anguilla rostrata) which uses anguilliform motion (undulatory body waves initiated at the nose with maximum amplitude at the tail) has a propulsive efficiency estimated at $0.43-0.54$ based on wake studies, Tytell and Lauder (2004). Whilst labriform swimming (a type of Median and/or Paired Fin (MPF) propulsion, in which the species uses a control surface other than the tail to swim) have significantly lower propulsive efficiencies $0.15-0.2$ for a bluegill sunfish (Lepomis macrochirus), Jones et al. (2007). However, labriform swimming is largely performed by non-pelagic fish where increased manoeuvrability is required to negotiate complex environments. Labriform swimmers swim primarily with their pectoral fins, using their caudal fin to assist only at higher speeds. These species possess a swim bladder and are 
thus able to maintain neutral buoyancy. The transition, from pectoral to pectoral and caudal fin gaits, termed the pectoral-caudal gait transition speed, Drucker (1996), occurs at a threshold speed that varies between species and individual size, Mussi et al. (2002). The ability to maintain the pectoral and caudal fin gait for long periods also varies between species, Korsmeyer et al. (2002). Drucker and Lauder (2000), measured the gait transition speed for black surfperch (Embiotoca jacksoni) and the bluegill sunfish (Lepomis macrochirus); for individuals of $20 \mathrm{~cm}$ length the $\mathrm{U}_{\mathrm{p}-\mathrm{c}}$ was $2.0 \mathrm{BL} . \mathrm{s}^{-1}$ (Body Lengths per second) for the surfperch and $1.5 \mathrm{BL} . \mathrm{s}^{-1}$ for the sunfish.

High potential propulsive efficiencies have led to significant research effort being applied to mimicking biological propulsion systems in preference to the more conventional screw propeller. For example see Draper Laboratory VCUUV robotic tuna, Anderson and Chhabra (2002), robotic dolphin, Yu et al. (2009), Finnegan robotic turtle, Wolf et al. (2006), Biomimetic Tuna, Suleman and Crawford (2008) and the review by Roper et al. (2011). However the propulsive efficiency only considers the ability of the motion of the propulsor to generate hydrodynamic thrust (and shaft losses for AUVs). No account is made for the additional losses incurred generating the shaft motion, or energy losses earlier in the energy flow (see Figure 1).

In nature motion is created using muscles. Biological muscles for vertebrates can be separated into four groups: fast and slow skeletal muscles, smooth muscles and cardiac muscles, OOta and Saitou (1999). Skeletal muscles will be the main interest for studying propulsion, as it is the only type that can be consciously controlled, and is responsible for actuating all limbs or propulsors. Skeletal muscles are made up of two types of muscle fibres, slow twitch (Type I) and fast twitch (Type II). Biological muscles are not very efficient compared to rotary electric motors, but their efficiency is superior to that of manmade linear actuators. Typically, skeletal muscles are typically only 0.3 efficient, although certain types can reach 0.5, Curtin and Woledge (1993a). Adenosine triphosphate ATP is the main energy source for the majority of cellular functions. Contraction of the muscle fibres is powered by the energy released by the breakdown of ATP to Adenosine diphosphate (ADP) and a phosphate ion. The energy released in cells by the breaking down of foodstuffs can be used to recombine the ADP and phosphate ion to reform ATP, this process is only 0.5 efficient, Alexander (2003). Study of biological muscles in robotics is often restricted to being the target for comparison with man-made systems, Caldwell (1993). However, attempts have been made to graft living biological muscle to actuate underwater vehicles, Herr and Dennis (2004). The field of biomechatronics is still in its infancy, and sustaining the living muscle ex-vivo is a considerable challenge.

For engineered artefacts there are a number of technologies used in converting stored chemical energy into kinetic energy. These can be divided into two groups: namely rotary or linear. The rotary actuators are the most common and can be subdivided into three types, electric motors, hydraulic motors and heat engines. Linear actuators are less common but include a large variety of actuation technologies. These include shape memory alloys, electro active polymers, and hydraulic pistons. Linear actuators are mainly used in bio-inspired propulsion systems. Also, linear actuation may be achieved using rotary actuators. Often these include a conversion component, such as pulleys, rack and pinion, screws, hydraulic pumps, etc. Table 1 provides a guide to typical actuator efficiencies.

Most biomimetic propulsion systems require oscillating or reciprocating motion. In the majority of systems this is achieved by using a rotary electric motor connected to a gearing 
system. Some control the motions electronically by varying motor output through a sinusoidal cycle, Licht et al. (2004a) others achieve it using a cam and cranks, Yu et al. (2009). Pneumatic and hydraulic cylinders are common in land robot systems, but less common in AUVs. 
Table 1: - Typical actuator efficiencies (shaded rows correspond to biological actuators).

\begin{tabular}{|c|c|c|c|}
\hline Actuator Type & $\begin{array}{l}\text { Typical } \\
\text { Efficiencies }\end{array}$ & Comments & Source \\
\hline $\begin{array}{l}\text { Direct Current (DC) } \\
\text { Motor }\end{array}$ & $0.6-0.9$ & $\begin{array}{l}\text { Commonest form of actuator used to propel an AUV. The quoted efficiencies are maximum } \\
\text { motor efficiencies at optimum continuous loading. Efficiency varies with size and motor } \\
\text { design. }\end{array}$ & Maxon (2011) \\
\hline Pneumatic cylinders & $<0.67$ & $\begin{array}{l}\text { However, the efficiency is highly dependent on other variables and highly dependent on other } \\
\text { components in the pneumatic system, so most are much less efficient than this theoretical } \\
\text { maximum. }\end{array}$ & $\begin{array}{l}\text { Prior and White } \\
\text { (1995) }\end{array}$ \\
\hline $\begin{array}{l}\text { Dogfish } \\
\text { (Scykiorhinus } \\
\text { canicula) red muscle } \\
\text { fibres (Type I) }\end{array}$ & $<0.507$ & $\begin{array}{l}\text { Muscle fibres isolated from the dogfish were electrically stimulated at } 12^{\circ} \mathrm{C} \text {. The resulting } \\
\text { efficiency for sinusoidal motion varies with frequency, with maximum efficiency at } 0.61- \\
0.95 \mathrm{~Hz} \text { and maximum power at } 1.02 \mathrm{~Hz} \text {. }\end{array}$ & $\begin{array}{l}\text { Curtin and } \\
\text { Woledge } \\
\text { (1993a) }\end{array}$ \\
\hline $\begin{array}{l}\text { Dogfish } \\
\text { (Scykiorhinus } \\
\text { canicula )white } \\
\text { muscle fibres (Type } \\
\text { II) }\end{array}$ & $<0.41$ & $\begin{array}{l}\text { Muscle fibres isolated from the dogfish were electrically stimulated at } 12^{\circ} \mathrm{C} \text {. The resulting } \\
\text { efficiency for sinusoidal motion varies with frequency, with maximum efficiency at } 2.0-2.5 \mathrm{~Hz} \\
\text { and maximum power at } 3.5 \mathrm{~Hz} \text {. }\end{array}$ & $\begin{array}{l}\text { Curtin and } \\
\text { Woledge } \\
(1993 b)\end{array}$ \\
\hline Diesel Engine & $<0.4$ & $\begin{array}{l}\text { The chief advantage of a heat engine is that combustion fuels typically have much higher } \\
\text { specific energy than batteries. However they do require a source of oxygen, which may be } \\
\text { taken from the air using a snorkel. University of Tokyo's R-one Robot is one of a handful of } \\
\text { AUVs that uses an air independent internal combustion engine. R-one robot carries a closed } \\
\text { cycle diesel engine and liquid oxygen. }\end{array}$ & $\begin{array}{l}\text { Ura and Obara } \\
(1999)\end{array}$ \\
\hline $\begin{array}{l}\text { Bluegill Sunfish } \\
\text { (Lepomis } \\
\text { macrochirus) } \\
\text { propulsion muscles }\end{array}$ & $\begin{array}{l}0.37 \text { to } \\
0.26\end{array}$ & $\begin{array}{l}\text { Efficiency estimate at maximum labriform swimming speed, based on the upper and lower } \\
\text { estimates of available mechanical power respectively. Total swimming power required was } \\
\text { estimated based on oxygen consumption. }\end{array}$ & $\begin{array}{l}\text { Jones et al. } \\
(2007)\end{array}$ \\
\hline $\begin{array}{l}\text { Electroactive } \\
\text { Polymers }\end{array}$ & $<0.38$ & $\begin{array}{l}\text { Electroactive polymer is a new form of polymer linear actuator, which changes shape when a } \\
\text { current is applied. There are two types of EAP, electronic and ionic. The main difference }\end{array}$ & $\begin{array}{l}\text { Bar-Cohen } \\
(2004)\end{array}$ \\
\hline
\end{tabular}


between the two types of EAP is that the former uses Coulomb forces and the latter uses ion movement.

Shape memory alloy (SMA) actuators function by heating and cooling the alloy to induce a phase transition. The resultant change in the crystal lattice cause a change in the overall shape of the SMA which result in a force. The speed of the actuation depends on heating and cooling

Humbeeck (2001) hysteresis as heating and cooling phase transitions occurs at different temperatures. 
The typical rotation speeds of DC motors or engine output shafts are too fast for efficiently driving a propeller, thus a reduction gearbox is often used. Exceptions include the direct drive motors used on the Autosub3 and Autosub6000 vehicles. The efficiency of different gearboxes varies: a one-stage planetary gear can be over $90 \%$ efficient, while a worm drive can be as little as $40 \%$. Generally the greater the reduction ratio, the lower the gear box efficiency, Maxon (2011).

An alternative actuation and propulsion method is the buoyancy engine used on glider vehicles. A pump is used to effect buoyancy changes to make the glider system positively or negatively buoyant. The resulting potential energy is converted to kinetic energy through the use of wings. The total system efficiency for a glider is at best 0.5 (occurring for the deepest depth range), Griffiths (2003). Using a well matched propeller, motor and gearbox system it should be possible to achieve similar propulsive system efficiencies, Furlong et al. (2007), see Table 2 .

Table 2 - Comparison of propulsion system efficiencies

\begin{tabular}{|c|c|c|c|}
\hline \multicolumn{2}{|c|}{ Buoyancy engine } & \multicolumn{2}{|c|}{ Propeller system } \\
\hline \multirow[t]{5}{*}{ Propulsive system efficiency } & $<0.5$ & Propulsive efficiency & 0.7 \\
\hline & & Shaft efficiency & 0.95 \\
\hline & & Gearbox efficiency & 0.9 \\
\hline & & Motor efficiency & 0.9 \\
\hline & & Propulsion system efficiency & 0.53 \\
\hline
\end{tabular}

Assuming ATP conversion efficiency of 0.5 and a muscle efficiency of 0.5 then a pseudo killer whale with a propulsive efficiency of 0.9 will have a propulsion system efficiency of 0.225 , significantly lower than the 0.5 that can be achieved with an engineered propeller or buoyancy change system. For subcarangiform swimmers, Webb (1975), suggests that total propulsion system efficiencies (overall aerobic efficiency) are commonly in the range 0.15 0.3 .

As such, extreme care must be made when designing a propulsion system to ensure that the actuator efficiency is sufficiently high. However, the objective of this type of research is not always to make efficient actuators, but to investigate the hydrodynamics, logic and mechanism of biological systems; e.g. simple mimicry, where many underwater vehicles with biomimetic propulsors either quote poor total propulsion system efficiencies, Yu et al. (2009) or total propulsion system efficiency is not quoted at all, Cai et al. (2010); Suleman and Crawford (2008). In many cases a propeller driven AUV would be able to achieve the same speed as a vehicle using bio-inspired propulsion but at a lower propulsive system power, for example, Licht et al. (2004b). 


\section{Optimum Cost of Transport}

For both pelagic marine animals and AUVs it is common to transit at or near $U_{\text {opt }}$ minimising the COT and in the case of AUVs maximising the range, Sato et al. (2010). Figure 9 compares the optimum cost of transport, $C O T_{\text {opt }}$, for various marine animals and AUVs.

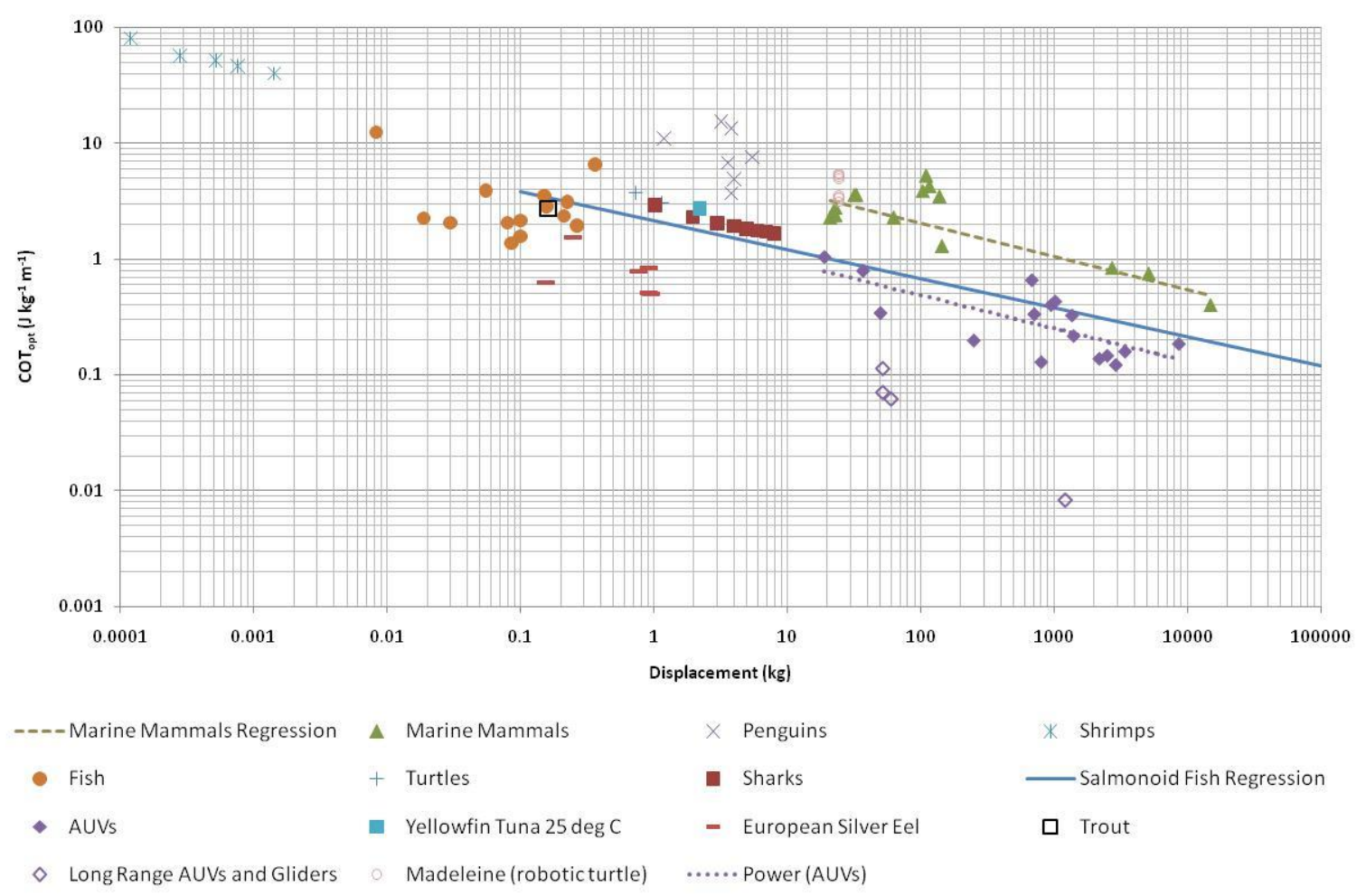

Figure 9 - Comparison of the optimum cost of transport versus mass for various types of marine animals $(n=56)$ and AUVs $(n=22)$. For AUVs the mass quoted is the displaced mass corresponding to the outer hull volume, and thus includes the mass of water in free flooding spaces in the hull. Data for Madeleine a robotic turtle from Long Jr et al. (2006). Data for shrimps, turtles, fish summarised in Videler and Nolet (1990). For mammals the data is taken from Williams (1999); Rosen and Trites (2002); Videler and Nolet (1990). Data for yellowfin tuna from Dewar and Graham (1994), squid Webber and O'Dor (1986). Data for penguins summarised in Luna-Jorquera and Culik (2000). Bonnethead shark (the smallest of the hammerhead sharks) data from Parsons (1990). Silver eel data from van Ginneken et al. (2005) and collated by Palstra and van den Thillart (2010), where multiple measurement techniques are used an average value has been taken. Trout data from van Ginneken et al. (2005). Regression line for salmonoid fish taken from Brett (1964), and for marine mammals from Williams (1999). The apparently anomalous data point at $\sim 1100 \mathrm{~kg}$ and $<0.01 C_{\text {COpt }}$ corresponds with the AutosubLR, which is currently under development, its position on the graph is clarified in Figure 10, where its $C O T_{\text {opt }}$ is consistent with its mass and hotel load (1W design).

Also included on the figure are three regression lines. For salmonoid fish Brett (1964) presents an extrapolated regression:

$$
\operatorname{COT}_{O P T}=2.15 \text { mass }^{-0.25}
$$


For mammals Williams (1999) suggests the following regression line $\left(\mathrm{R}^{2}=0.83\right)$ for marine mammals from $21 \mathrm{~kg}$ to $15000 \mathrm{~kg}$ :

$$
\operatorname{COT}_{O P T}=7.79 \text { mass }^{-0.29}
$$

Fitting an equivalent regression line through all the AUV data highlights the scatter and variation in the data. The resulting line (not plotted on Figure 9 for clarity) has the form:

$$
\operatorname{COT}_{O P T}=0.4149 \text { mass }^{-0.123}
$$

With an $\mathrm{R}^{2}$ value of 0.043 , its only value is to highlight the variability. By removing the three gliders and the AutosubLR from the data (as arguably these form a different class of vehicle) a more meaningful regression line is generated

$$
\operatorname{COT}_{O P T}=1.813 \text { mass }^{-0.285}
$$

which has an $\mathrm{R}^{2}$ value of 0.5248 . This line corresponds to a faster reduction in COT with increasing size than the regression lines for salmonoid fish, while the exponents for AUVs and marine mammals are essentially identical. Based on the regression lines a typical AUV has a COT 4.3 times smaller than a marine mammal of similar displacement.

While there is significant scatter in the data for both the AUVs and marine mammals, as expected from the simplified model, increasing displaced mass tends to lead to a reduction in $C O T_{\text {opt }}$. It is also apparent that the AutosubLR and gliders have significantly lower cost of transport than normal AUVs of similar size; this is required for these vehicles to achieve their desired ranges, their designers have accepted that all non-propulsion power requirements including science sensors should be low (order $1 \mathrm{~W}$ ), and that the forward speed will also be low (order 0.3 to $0.4 \mathrm{~m} / \mathrm{s}$ ) to ensure operation at $C O T_{\text {opt }}$.

There is a notable distinction between the $C O T_{\text {opt }}$ for warm blooded and cold blooded marine animals. Williams (1999) also noted that the $C O T_{\text {opt }}$ of transport for marine mammals is considerably higher than those extrapolated for salmonoid fish of the same mass. This was attributed to the difference in maintenance cost (hotel load) between the two groups due to the inherent difference in endothermy. By removing the energetic cost of maintaining endothermy, Williams (1999) showed that the $C O T_{\text {opt }}$ of marine mammals tended to those of salmanoid fish.

Similarly, the measured metabolic rates of tuna exceed those of other well studied fishes (salmonoids) by approximately threefold, Korsmeyer and Dewar (2001), thus explaining the higher $C O T_{\text {opt }}$ of Yellowfin tuna compared to salmonoid fish. The high $C O T_{\text {opt }}$ of penguins may be attributed to the reports that some diving birds incur high substantial thermoregulatory energetic costs, Leeuw et al. (1998); Grémillet et al. (2005).

It is interesting to note the comparatively low COT of the silver eel compared to the trout (both data points are for similar sized animals). This may initially seem at odds with the previously stated observation that carangiform propulsion (as for the trout) has a high propulsive efficiency compared to anguilliform propulsion (for the eel) Tytell and Lauder (2004) but this is an example where the whole system efficiency is what is reflected in the COT. Since neither the trout or the silver eel have high drag body shapes it is probable that the difference is due to high metabolic efficiency (low BMR) in the Silver eel, van Ginneken et al. (2005), also see Figure 6. Such an argument is supported by Clarke and Johnston (1999) 
who illustrate the low resting $\mathrm{O}_{2}$ consumption of eels compared to other common fish types. Similarly, Pettersson and Hedenstrom (2000) illustrated that increased propulsive power requirements of high drag bodies may be offset by reducing the BMR to achieve similar COT values.

For most bio-inspired AUVs there is insufficient data to calculate COT, the robotic turtle Madeleine, Long Jr et al. (2006), is an exception. COT data is available for a range of gaits based on either two or four flipper locomotion; these COT values are similar in magnitude to marine animals of similar sizes, but higher than similar sized AUVs.

Considering the similarity in form and propulsion method of most AUVs there is surprising scatter in the AUV COT $T_{\text {opt }}$ data, which covers a much wider range of $C O T_{\text {opt }}$ compared to marine animals of the same size. As highlighted in the previous section $C O T_{\text {opt }}$ is highly sensitive to the hotel load. Figure 10 shows the influence of hotel load on $C O T_{\text {opt }}$, using the same methodology as before, assuming, $\rho=1025 \mathrm{~kg} / \mathrm{m}^{3} v=1.19 \times 10^{-6}, L / D=7$ and $\eta_{D} \eta_{a}=0.5$.

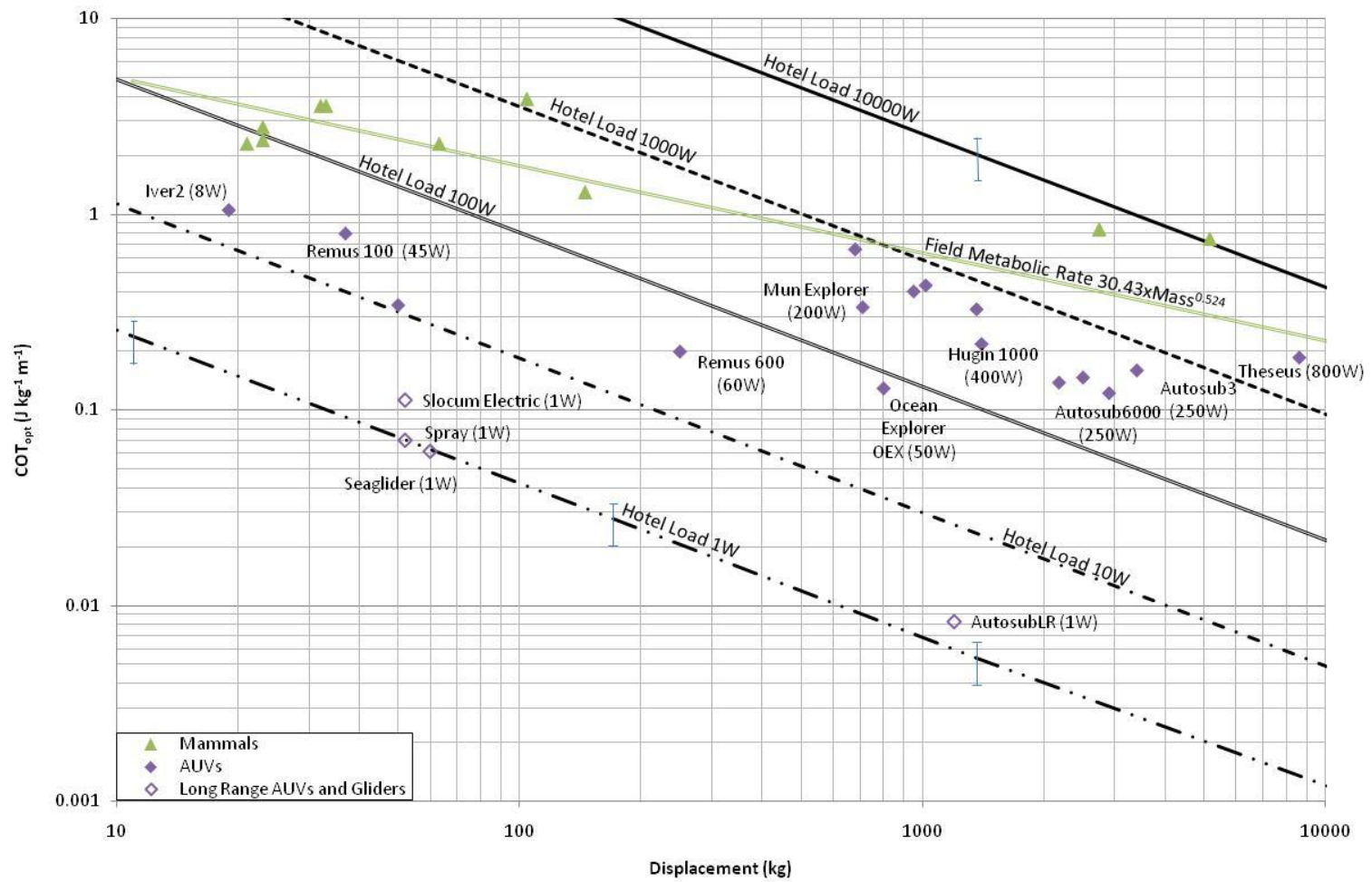

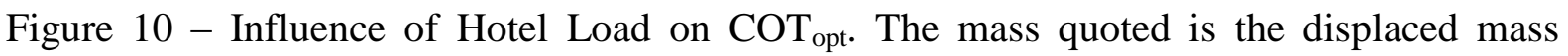
corresponding to the outer hull volume, and thus includes the mass of water in free flooding spaces in the hull. The diagonal black lines represent the predicted $C O T_{\text {opt }}$ for various hotel loads assuming, $\eta_{D} \eta_{a}=0.5, \mathrm{~L} / D=7, P_{H}=50 \mathrm{~W}, \rho=1025 \mathrm{~kg} / \mathrm{m}^{3}$ and $v=1.19 \times 10^{-6} \mathrm{~m}^{2} \mathrm{~s}^{-1}$. The field metabolic rate (FMR) is the resting metabolic rate in the field, FMR relationship taken from Boyd (2002). Included in the Hotel Load 1W line and the Hotel Load 10,000W line are error bars indicating the influence of reducing the propulsion power by a factor of two and increasing the propulsion power by a factor of two.

Also where known the hotel load of the various vehicles are indicated on the plot. From this plot it becomes clear that the variability in the $C O T_{\text {opt }}$ of AUVs is closely linked to the variability of their hotel loads, which range from the order of one thousand watts for Theseus, 
Butler (1999), to an actual hotel load of approximately 1W for the three commonest gliders and the design hotel load for AutosubLR (currently $\sim 7 \mathrm{~W}$ ). Comparing the AUV data points to the predicted $C O T_{\text {opt }}$ with different hotel loads suggest that the simple model captures well the observed variation. The simple model is also relatively well able to capture the $C O T_{\text {opt }}$ for marine mammals by assuming that the field metabolic rate is equivalent to hotel load and using the regression line from Boyd (2002).

Traditionally, survey style AUVs have been designed with a cruising speed of around $2 \mathrm{~m} / \mathrm{s}$ as a compromise between maximising the range and the need to make reasonable progress, Stevenson et al. (2007). For many vehicles this velocity is close to $U_{o p t}$. With a reduction in hotel load $U_{\text {opt }}$ also reduces and may well reduce significantly below $2 \mathrm{~m} / \mathrm{s}$ (e.g. to $\sim 0.3 \mathrm{~m} / \mathrm{s}$ for AutosubLR at $1 \mathrm{~W}$ hotel load). With this, many AUVs may start to operate routinely at speeds higher than $U_{\text {opt }}$, where both propulsive efficiency and drag coefficient play an important role in the COT of the vehicle. Petterson and Hedenstrom (2000) showed that low drag fishes can use a broader range of swimming velocities without substantial increase in energetic cost, while high drag fish have a marked increase in swimming costs. Similar results are observed for AUVs with low $\mathrm{C}_{\mathrm{Dv}}$ and high propulsive efficiencies, Figure $5 \mathrm{~d}$.

\section{Discussion}

The data presented in this chapter corrects the common misconception that marine animals have greater propulsion system efficiencies than engineered systems of an equivalent size. This does not mean that marine animals should not be a source of inspiration just that care should be taken in identifying sources of inspiration. For example, for AUV designers interested in metrics other than level flight performance, such as manoeuvring, bio-inspired propulsion systems have clearly demonstrated improved performance, Anderson et al. (1998).

This discussion has concentrated its attentions on cost of transport and energetic requirements while travelling in a straight line. For the marine animals, no account has been taken of potential penalties associated with high manoeuvrability, such as large control fins, which may lead to increased drag for straight ahead swimming, or adaptations to improve reproduction success rates. Also energy expenditure associated with maintaining depth for non-neutrally buoyant systems has not been considered explicitly; this is an issue for animals and AUVs.

Away from free stream operating conditions the preference of fish to use unsteady flow features has been observed in both the laboratory Webb (1998); Liao et al. (2003) and the field Hinch and Rand (2000); Fausch (1993); McLaughlin and Noakes (1998). The potential of replicating such behaviours with AUVs is discussed in Philips et al. (2010).

Along with its cost of transport, another key metric in determining the ability of an AUV to obtain its design range is the amount of energy stored on board the vehicle. Conventional AUVs carry a finite amount of chemical energy (batteries or fuel) which is used for both propulsion and hotel load. Hence, to maximise the vehicle's range at a specific speed, the AUV designer must minimise the cost of transport while optimising the specific energy of the power source. There are many types of power sources. Often the selection is determined by the choice of propulsion system, mission requirement and size and weight limitations. The most common power sources in AUVs are electrical batteries, where potential chemical energy is stored. Batteries can be approximately modelled as a voltage source in series with a resistance, this internal resistance of a battery is dependent on the specific battery's size, 
chemical properties, age, temperature and the discharge current. However, other types of power source do exist, these include chemical fuel, such as diesel, Otto fuel II, compressed hydrogen among others. Fuller discussions of engineered technologies may be found in Hasvold et al. (2006); Bradley et al. (2001); Griffiths et al. (2004). The specific energy of some common forms of energy storage in the natural and engineered world are compared in Table 2. The fats used in nature as energy stores have significantly higher specific energies than current battery technologies, for example, fish oils have a specific energy over 60 times greater than lithium polymer batteries.

Table 3-Comparison of specific energy of various energy storage methods both biological and engineered. Shaded rows correspond to biological energy stores.

\begin{tabular}{lll}
\hline \hline Energy Storage Type & $\begin{array}{l}\text { Specific Energy } \\
(\mathrm{MJ} / \mathrm{kg})\end{array}$ & Reference \\
\hline \hline Diesel & 40.0 & $\begin{array}{l}\text { Larminie and Lowry } \\
(2003)\end{array}$ \\
Fish Oil (Cod Liver Oil) & 39.45 & $\begin{array}{l}\text { Liversey and Elia } \\
(1988)\end{array}$ \\
$\begin{array}{l}\text { Bowhead Whale (Balaena mysticetus) } \\
\text { subcutaneous fat (Blubber) }\end{array}$ & 36.4 & $\begin{array}{l}\text { U.S. Department of } \\
\text { Agriculture (2010) }\end{array}$ \\
$\begin{array}{l}\text { Gray seal (Halichoerus grypus) blubber } \\
\begin{array}{l}\text { White beaked dolphin (Lagenorhynchus } \\
\text { albirostris) blubber }\end{array}\end{array}$ & 32.7 & $\begin{array}{l}\text { This study } \\
\text { This }\end{array}$ \\
$\begin{array}{l}\text { Otto Fuel II (mono propellant) } \\
\begin{array}{l}\text { Lithium Polymer Battery } \\
\text { Nickel Metal hydride (Ni-MH) }\end{array}\end{array}$ & 5.04 & Luo et al. (2008) \\
\hline \hline
\end{tabular}

${ }^{1}$ Tested in a calorimeter, blubber samples were taken from the middle body part of a white beaked dolphin and a gray seal, both stranded and specially the dolphin suffered from malnutrition; therefore the blubber had changed in texture (rubbery instead of jelly) and colour, therefore there is the assumption that the resulting specific energy might be less than one of a healthy animal.

Typically batteries account for between $5 \%$ and $45 \%$ of an AUV's mass, dependent on mission, range, depth and speed requirements, Griffiths et al. (2004). Marine animals are able to acquire additional energy through feeding to replenish the energy used through routine behaviours and so the energy stored by various marine animals varies with species, sex, season, migratory stage, feeding behaviour and age among other variables, Jonsson et al. (1997); Anthony et al. (2000); Struntz et al. (2004). In a study in Prince William Sound, Alaska, shrimps and octopus had the lowest average fat content at $\sim 1 \%$, while the highest fat contents were found in adult eulachon (25\%) and adult herring (21\%), Iverson et al. (2002). In Bottlenose Dolphins (Tursiops truncates) blubber accounts for between 15 and $27 \%$ of an adult animal's total mass, Struntz et al. (2004). Blubber not only provides an energy store for marine mammals it is multifunctional, providing buoyancy, streamlining and functions in thermoregulation Struntz et al. (2004).

It is assumed that silver eels make the $6000 \mathrm{~km}$ journey back to their spawning ground without feeding, Schmidt (1923); van Ginneken and Maes (2005). van Ginneken et al. (2005) , simulated a 5500km migration by placing female silver eels in a swim tunnel. Nine individuals with an average mass of $914.7 \mathrm{~g}$ completed the simulated migration at $0.5 \mathrm{BL} . \mathrm{s}^{-1}$ $(\sim 0.37 \mathrm{~m} / \mathrm{s})$ using an average of $3.45 \mathrm{MJ} . \mathrm{kg}^{-1}$. The fat content of silver eels prior to migration 
ranges from 10 to $28 \%$, Svedang and Wickstrom (1997). Assuming a fat energetic content of $39.45 \mathrm{MJ}_{\mathrm{kg}} \mathrm{kg}^{-1}$, the silver eel will have remaining fat reserves to allow for reproduction on arrival. Based on the above energetic values, no current secondary battery technology would allow a $1 \mathrm{~kg}$ engineered silver eel with $20 \%$ mass of batteries with equivalent propulsion and hotel power requirements to complete more than around $200 \mathrm{~km}$.

In a similar manner to the feeding behaviour of marine animals, not all AUVs rely solely on their onboard energy supply for the whole duration of their mission, for example the Naval Underwater Warfare Center's SAUV is solar powered, Crimmins et al. (2006) and Teledyne's Slocum Thermal Glider, Webb et al. (2001) uses the vertical ocean temperature gradient to generate volume changes.

\section{Conclusions}

Optimum cost of transport provides a useful metric for comparing the total energetic requirements of marine animals and AUVs. AUVs in general have a much wider range of $C O T_{\text {opt }}$ compared to marine animals; this is attributed to the much greater variability in AUV hotel load per unit mass than marine animal BMR per unit mass. In general AUVs have a lower $C_{\text {opt }}$ than equivalent sized marine animals, and are therefore, as complete systems, more energy efficient than their natural counterparts.

Marine animals and AUVs with low drag coefficients and high propulsion system efficiencies are able to operate over a wide range of speeds around $U_{\text {opt }}$ without incurring significant energetic penalties, unlike those with high drag or low propulsion system efficiencies. Consequently, for AUVs which operate above $U_{\text {opt }}$ minimising the propulsive power requirements has a significant impact on the range of the vehicle.

Typically Seaglider AUVs have achieved long ranges in excess of $4900 \mathrm{~km}$ by reducing their hotel load below $1 \mathrm{~W}$. Other long range gliders and AUVs have also adopted the approach of minimising their hotel load to maximise the range. In order to reduce the hotel load sufficiently, significant sacrifices are required in terms of type and frequency of measurements that may be taken. Marine animals can achieve equivalent migrations (for example silver eel at $5500 \mathrm{~km}$ ) by having high metabolic efficiencies (low base metabolic rates) and taking advantage of high specific energy fat stores which have specific energies 60 times that of the best secondary battery technologies.

When assessing the propulsive power requirements of an AUV or marine animal it is vital that all aspects of the system are considered, from actuator and shafts to the propulsor's interaction with the fluid. The high propulsive efficiency of thunniform propulsion (in which thrust is produced by oscillation of the tail involving very little bending of the body) coupled with the comparatively poor efficiency of muscle results in an overall efficiency that may be significantly lower than a conventional propeller and DC motor combination.

\section{Acknowledgements}

This research was supported by the EPSRC through grant number EP/F066767/1 entitled "Nature in Engineering for Monitoring the Oceans (NEMO)" a joint project between the University of Southampton, Newcastle University and the National Oceanography Centre. The overall aim of this project is to find and synthesize novel design and implementation concepts for deep-diving and agile unmanned underwater vehicles (UUV) to meet offshore 
industry, environmental monitoring and scientific research needs based on inspiration from marine organisms to achieve increased functionality, lower weight and energy requirements and lower capital and operational costs.

\section{References}

Alexander, R. M. (2003) Principles of animal locomotion, Princeton University Press.

Alexander, R. M. (2005) Models and scaling of energy costs for locomotion. Journal of Experimental Biology, 208, 1645-1652.

Allen, B., Vorus, W. S. \& Prestero, T. (2000) Propulsion system performance enhancements on REMUS AUVs. In. OCEANS 2000 MTS/IEEE Conference and Exhibition Providence, RI , USA, 11 - 14 Sep.

Anderson, I. A., leropoulos, I. A., Mckay, T., O'brien, B. \& Melhuish, C. (2011) Power for robotic artificial muscles. IEEE/ASME Transactions on Mechatronics, 16, 107-111.

Anderson, J. M. \& Chhabra, N. K. (2002) Maneuvering and stability performance of a robotic tuna. Integrative and Comparative Biology, 42, 118-126.

Anderson, J. M., Streitlien, K., Barrett, D. S. \& Triantafyllou, M. S. (1998) Oscillating foils of high propulsive efficiency. Journal of Fluid Mechanics, 360, 41-72.

Anthony, J. A., Roby, D. D. \& Turco, K. R. (2000) Lipid content and energy density of forage fishes from the northern Gulf of Alaska. Journal of Experimental Marine Biology and Ecology, 1, 5378.

Bar-Cohen, Y. (Ed.) (2004) Electroactive Polymer (EAP) Actuators as artificial muscles: reality, potential, and challenges, SPIE- The International Society for Optical Engineering.

Blake, R. W. (1979) The mechanics of labriform locomotion in the angelfish (Pterophyllum eimekei): an analysis of the power stroke. Journal of Experimental Biology, 82, 255-271.

Bose, N. \& Lien, J. (1989) Propulsion of a fin whale (Balaenoptera physalus): why the fin whale is a fast swimmer. Proceedings of the Royal Society of London. Series B, Biological Sciences, 237, 175-200.

Bourne, W. (1578) Inventions or devices. Very necessary for all generalles and captaines, as wel by sea as by land.

Boyd, I. L. (2002) Energetics: Consequences for Fitness. In Hoelzel, A. R. (Ed.) Marine Mammal Biology: An Evolutionary Approach. Blackwell Publishing.

Bradley, A. M., Feezor, M. D., Singh, H. \& Sorrell, F. Y. (2001) Power systems for autonomous underwater vehicles. IEEE Journal of Oceanic Engineering, 26, 526-538.

Brett, J. R. (1964) The respiratory metabolism and swimming performance of young sockeye salmon. Journal of Fisheries Research Board Canada, 21, 1183-1226.

Butler, B. (1999) Field Trials of the THESEUS AUV, World Wide Web, http://www.ise.bc.ca/auv1002.html, 18/02/2011.

Cai, Y., Bi, S. \& Zheng, L. (2010) Design and experiments of a robotic fish imitating cow-nosed ray. Journal of Bionic Engineering, 7, 120-126.

Caldwell, D. G. (1993) Natural and artificial muscle elements as robot actuators. Mechatronics, 3, 269-283.

Carlton, J. (2007) Marine propellers and propulsion, Butterworth-Heinemann.

Casellini, M. (2008) Thermoregulation. In Perrin, W. F., Wursig, B. \& Thewissen, J. G. M. (Eds.) Encyclopedia of marine mammals. London, Academic Press.

Clarke, A. \& Johnston, N. M. (1999) Scaling of metabolic rate with body mass and temperature in teleost fish. Journal of Animal Ecology, 68, 893-905.

Comstock, J. P. (1977) Principles of naval architecture, 4th Edition, SNAME. 
Crimmins, D. M., Patty, C. T., Beliard, M. A., Baker, J., Jalbert, J. C., Komerska, R. J., Chappell, S. G. \& Blidberg, R. D. (2006) Long-endurance test results of the solar-powered AUV system. In. Oceans 2006, Boston, MA, 18-21 Sept, 1-5.

Curtin, N. A. \& Woledge, R. C. (1993a) Efficiency of energy conversion during sinusoidal movement of red muscle fibres from the dogfish Scyliorhinus canicula. Journal of Experimental Biology, 185, 195-206.

Curtin, N. A. \& Woledge, R. C. (1993b) Efficiency of energy conversion during sinusoidal movement of white muscle fibres from the dogfish Scyliorhinus canicula. Journal of Experimental Biology, 183, 137-147.

Davis, R. W., Williams, T. M. \& Kooyman, G. L. (1985) Swimming metabolism of yearling and adult harbor seals Phoca vitulina. Physiological Zoology, 58, 590-596.

Dewar, H. \& Graham, J. B. (1994) Studies of tropical tuna swimming performance in a large water tunnel. I. Energetics. Journal of Experimental Biology, 192, 13-31.

Dong, H. (2005) Wake structure and performance of finite aspect-ratio flapping foils In. 43rd AIAA Aerospace Sciences Meeting and Exhibit, Reno, Nevada Jan. 10-13.

Dressler, F. (2005) Efficient and scalable communication in autonomous networking using bioinspired mechanisms - an overview Informatica 29, 183-188.

Drucker, E. G. (1996) The use of gait transition speed in comparative studies of fish locomotion. American Zoology, 36, 555-566.

Drucker, E. G. \& Lauder, G. V. (2000) A hydrodynamic analysis of fish swimming speed: wake structure and locomotor force in slow and fast labriform swimmers. Journal of Experimental Biology, 203, 2379-2393.

Elliott, J. M. \& Davison, W. (1975) Energy equivalents of oxygen consumption in animal energetics Oecologia, 19, 195-201.

Fausch, K. D. (1993) Experimental analysis of microhabitat selection by juvenile steelhead (Oncorhynchus mykiss) and coho salmon (O. kisutch) in a British Columbia stream. Canadian Journal of Fisheries and Aquatic Sciences 50, 1198-1207.

Fish, F. E. (1993) Power output and propulsive efficiency of swimming bottlenose dolphins (Tursiops truncatus). Journal of Experimental Biology, 185, 179-193.

Fish, F. E. (1996) Transitions from drag-based to lift-based propulsion in mammalian swimming. American Zoology, 36, 628-641.

Fish, F. E. (2006) The myth and reality of Gray's paradox: implication of dolphin drag reduction for technology. Bioinspiration \& Biomimetics, 2006, R17-R25.

Froese, R. \& Pauly, D. (2011) FishBase: version (02/2011), World Wide Web www.fishbase.org,

Furlong, M. E., Mcphail, S. D. \& Stevenson, P. (2007) A concept sesign for an ultra-long-range survey class AUV. In. Oceans 07, Aberdeen.

Gao, J., Bi, S., Li, J. \& Liu, C. (2009) Design and experiments of robot fish propelled by pectoral fins. In. IEEE International Conference on Robotics and Biomimetics, Guilin, China, December 19-23.

Grémillet, D., Kuntz, G., Woakes, A. J., Gilbert, C., Robin, J.-P., Maho, Y. L. \& Butler, P. J. (2005) Yearround recordings of behavioural and physiological parameters reveal the survival strategy of a poorly insulated diving endotherm during the Arctic winter. Journal of Experimental Biology, 208, 4231-4241.

Griffiths, G. (Ed.) (2003) Technology and applications of autonomous underwater vehicles, Taylor \& Francis.

Griffiths, G., Jamieson, J., Mitchell, S. \& Rutherford, K. (2004) Energy storage for long endurance AUVs. In. ATUV Conference, London, 16-17 March.

Hammer, C. (1995) Fatigue and exercise tests with fish. Comparative Biochemistry and Physiology Part A: Physiology, 112, 1-20.

Hasvold, $\varnothing$., Størkersena, N. J., Forsetha, S. \& Liana, T. (2006) Power sources for autonomous underwater vehicles. Journal of Power Sources, 162, 935-942. 
Herr, H. \& Dennis, R. G. (2004) A swimming robot actuated by living muscle tissue. Journal of NeuroEngineering and Rehabilitation, 1.

Heymsfield, S. B., Gallagher, D., Kotler, D. P., Wang, Z., Allison, D. B. \& Heshka, S. (2002) Body-size dependence of resting energy expenditure can be attributed to nonenergetic homogeneity of fat-free mass. American Journal of Physiology - Endocrinology and Metabolism, 282, E132E138.

Hinch, S. G. \& Rand, P. S. (2000) Optimal swimming speeds and forward-assisted propulsion: energyconserving behaviours of upriver-migrating adult salmon. Canadian Journal of Fisheries and Aquatic Sciences, 57, 2470-2478.

Hoerner, S. F. (1965) Fluid-dynamic drag, 2nd Edition, Published by the Author.

Huggins, R. A. (2010) Energy Storage, Springer.

Humbeeck, J. V. (2001) Shape memory alloys: a material and a technology. Advanced Engineering Materials, 3, 837-850.

Iverson, S. J., Frost, K. J. \& Lang, S. L. C. (2002) Fat content and fatty acid composition of forage fish and invertebrates in Prince William Sound, Alaska: factors contributing to among and within species variability. Marine Ecology Progress Series, 241, 161-181.

Ixsea (2011) IXSEA PHINS Surface Inertial Navigation System, World Wide Web, http://www.ixsea.com/en/navigation motion/3/phins.html, June 2011.

Jones, E. A., Lucey, K. S. \& Ellerby, D. J. (2007) Efficiency of labriform swimming in the bluegill sunfish (Lepomis macrochirus). Journal of Experimental Biology, 210, 3422-3429.

Jonsson, N., Jonsson, B. \& Hansen, L. P. (1997) Changes in proximate composition and estimates of energetic costs during upstream migration and spawning in Atlantic salmon Salmo salar. Journal of Animal Ecology, 66, 425-436.

Kleiber, M. (1932) Body size and metabolism. Hilgardia, 6, 315-353.

Korsmeyer, K. E. \& Dewar, H. (2001) Tuna metabolism and energetics. Fish Physiology, 19, 35-78.

Korsmeyer, K. E., Steffensen, J. F. \& Herskin, J. (2002) Energetics of median and paired fin swimming, body and caudal fin swimming, and gait transition in parrotfish (Scarus schlegeli) and triggerfish (Rhinecanthus aculeatus). Journal of Experimental Biology, 205, 1253-1263.

Larminie, J. \& Lowry, J. (2003) Electric Vehicle Technology Explained, John Wiley \& Sons Ltd.

Leeuw, J. J. D., Butler, P. J., Woakes, A. J. \& Zegwaard, F. (1998) Body cooling and its energetic implications for feeding and diving of tufted ducks. Physiological Zoology, 71, 720-730.

Liao, J. C., Beal, D. N., Lauder, G. V. \& Triantafyllou, M. S. (2003) The Kármán gait: novel body kinematics of rainbow trout swimming in a vortex street. Journal of Experimental Biology, 2006, 1059-1073.

Licht, S., Hover, F. \& Triantafyllou, M. S. (2004a) Design of a flapping foil underwater vehicle. International Symposium on Underwater Technology.

Licht, S., Polidoro, V., Flores, M. \& Hover, F. S. (2004b) Design and Projected Performance of a Flapping Foil AUV. Journal of oceanic engineering, 29, 786-794.

Lighthill, M. J. (1969) Hydromechanics of aquatic animal propulsion. Annual Review of Fluid Mechanics, 1, 413-446.

Lighthill, M. J. (1970) Aquatic animal propulsion of high hydromechanical efficiency. Journal of Fluid Mechanics, 44, 265-301.

Liversey, G. \& Elia, M. (1988) Estimation of energy expenditure, net carbohydrate utilization, and net fat oxidation and synthesis by indirect calorimetry: evaluation of errors with special reference to the detailed composition of fuels. The American Journal of Clinical Nutrition, 47, 608-628.

Long Jr, J. H., Schumacher, J., Livingston, N. \& Kemp, M. (2006) Four flippers or two? Tetrapodal swimming with an aquatic robot. Bioinspiration \& Biomimetics, 1, 20-29.

Luna-Jorquera, G. \& Culik, B. M. (2000) Metabolic rates of swimming Humboldt penguins. Marine Ecology Progress Series, 203, 301-309. 
Luo, N., Miley, G. H., Kim, K.-J., Burton, R. \& Huang, X. (2008) $\mathrm{NaBH}_{4} / \mathrm{H}_{2} \mathrm{O}_{2}$ fuel cells for air independent power systems Journal of Power Sources, 185, 684-690.

Maxon (2011) Maxon Motor, World Wide Web, www.maxonmotor.co.uk, June 2011.

Mclaughlin, R. L. \& Noakes, D. L. G. (1998) Going against the flow: an examination of the propulsive movements made by young brook trout in streams. Canadian Journal of Fisheries and Aquatic Sciences, 55, 853-860.

Mussi, M., Summers, A. P. \& Domenici, P. (2002) Gait transition speed, pectoral fin-beat frequency and amplitude in Cymatogaster aggregata, Embiotoca lateralis and Damalichthys vacca. Journal of Fish Biology, 61, 1282-1293.

Ohlberger, J., Staaks, G. \& Hölker, F. (2006) Swimming efficiency and the influence of morphology on swimming costs in fishes. Journal of Comparative Physiology B: Biochemical, Systemic, and Environmental Physiology, 176, 17-25.

Oota, S. \& Saitou, N. (1999) Phylogenetic relationship of muscle tissues deduced from superimposition of gene trees. Molecular Biology and Evolution, 16, 856-867.

Palstra, A. P. \& Van Den Thillart, G. E. E. J. M. (2010) Swimming physiology of European silver eels (Anguilla anguilla L.): energetic costs and effects on sexual maturation and reproduction. Fish Physiology Biochemisty, 36, 297-322.

Parsons, G. R. (1990) Metabolism and swimming efficiency of the bonnethead shark Sphyrna tiburo. Marine Biology, 104, 363-367.

Persistor Instruments Inc (2010) Persistor(R) CF2, World Wide Web, http://www.persistor.com/, June 2011.

Philips, A. B., Blake, J. I. R., Smith, B., Boyd S.W. \& Griffiths, G. (2010) Nature in engineering for monitoring the oceans: towards a bio-inspired flexible AUV operating in an unsteady flow. Proceedings of the Institution of Mechanical Engineers, Part M: Journal of Engineering for the Maritime Environment, 224, 267-278.

Phillips, A. B., Furlong, M. E. \& Turnock, S. R. (2007) The use of computational fluid dynamics to assess the hull resistance of concept autonomous underwater vehicles In. Oceans 2007 Europe, Aberdeen, 1-6.

Phillips, A. B., Turnock, S. R. \& Furlong, M. (2010) The use of computational fluid dynamics to aid cost-effective hydrodynamic design of autonomous underwater vehicles. Proceedings of the Institution of Mechanical Engineers, Part M: Journal of Engineering for the Maritime Environment, 224, 239-254.

Plaut, I. (2001) Critical swimming speed: its ecological relevance. Comparative Biochemistry and Physiology Part A: Physiology, 131, 41-50.

Pni (2011) FieldForce TCM, World Wide Web, http://www.pnicorp.com/products/fieldforce-tcm, June 2011.

Prior, S. D. \& White, A. S. (1995) Measurements and simulation of a pneumatic muscle actuator for a rehabilitation robot Simulation Practice and Theory, 3, 81-117.

Read, D. A., Hover, F. S. \& Triantafyllou, M. S. (2003) Forces on oscillating foils for propulsion and maneuvering. Journal of Fluids and Structures, 17, 163-183.

Reijniers, J. \& Peremans, H. (2007) Biomimetic Sonar System Performing Spectrum-Based Localization. IEEE Transactions on Robotics, 23, 1151-1159.

Roper, D. T., Sharma, S., Sutton, R. \& Culverhouse, P. (2011) A review of developments towards biologically inspired propulsion systems for autonomous underwater vehicles. Proceedings of the Institution of Mechanical Engineers, Part M: Journal of Engineering for the Maritime Environment, 225, 77-96.

Rosen, D. S. \& Trites, A. (2002) Cost of transport in steller sea lions, Eumetopias jubatus. Marine Mammal Science, 18, 513-524.

Sato, K., Shiomi, K., Watanabe, Y., Watanuki, Y., Takahashi, A. \& Ponganis, P. J. (2010) Scaling of swim speed and stroke frequency in geometrically similar penguins: they swim optimally to 
minimize cost of transport. Proceedings of the Royal Society of London. Series B, Biological Sciences, 277, 707-714.

Schmidt-Nielsen, K. (1997) Animal Physiology: Adaptation and Environment, 5th Edition, Cambridge University Press.

Schmidt, J. (1923) Breeding places and migration of the eel. Nature, 111, 51-54.

Smith, R. R. (1976) Studies on the energy metabolism of cultured fish, PhD Thesis, Cornell University. SNAME (1957) 8th International Towing Tank Conference. Madrid.

Stefoff, R. (2006) Submarines, Benchmark Books.

Stevenson, P., Furlong, M. \& Dormer, D. (2007) AUV shapes - combining the practical and hydrodynamic considerations. Oceans 2007- Europe. Aberdeen.

Struntz, D. J., Mclellan, W. A., Dillaman, R. M., Blum, J. E., Kucklick, J. R. \& Pabst, D. A. (2004) Blubber development in bottlenose dolphins (Tursiops truncatus). Journal of Morphology, 259, 7-20.

Suleman, A. \& Crawford, C. (2008) Design and testing of a biomimetic tuna using shape memory alloy induced propulsion. Computers and Structures, 86, 491-499.

Svedang, H. \& Wickstrom, H. (1997) Low fat contents in female silver eels: indications of insufficient energetic stores for migration and gonadal development. Journal of Fish Biology, 50, 475486.

Townsend, C. R. \& Winfield, I. J. (1985) The application of optimal foraging theory to feeding behaviour in fish. In Tyler, P. \& Calow, P. (Eds.) Fish Energetics: New Perspectives. Baltimore, Maryland, Johns Hopkins University Press.

Tytell, E. D. \& Lauder, G. V. (2004) The hydrodynamics of eel swimming I. Wake structure. Journal of Experimental Biology, 207, 1825-1841.

U.S. Department of Agriculture (2010) USDA national nutrient database for standard reference, release 23. nutrient data laboratory home page, World Wide Web, http://www.ars.usda.gov/nutrientdata,

Ura, T. \& Obara, T. (1999) Twelve hour operation of cruising type AUV "R-One Robot" equipped with a closed cycle diesel engine system. In. Oceans '99, Seattle, 1188-1193.

Van Ginneken, V. J. T., Antonissen, E., Müller, U. K., Booms, R., Eding, E., Verreth, J. \& Van Den Thillart, G. (2005) Eel migration to the Sargasso: remarkably high swimming efficiency and low energy costs. Journal of Experimental Biology, 208, 1329-1335.

Van Ginneken, V. J. T. \& Maes, G. E. (2005) The european eel (Anguilla anguilla, Linnaeus), its lifecycle, evolution and reproduction: a literature review. Reviews in Fish Biology and Fisheries, 15, 367-398.

Videler, J. J. (1993) Fish Swimming, Springer.

Videler, J. J. \& Nolet, B. A. (1990) Costs of swimming measured at optimum speed: Scale effects, differences between swimming styles, taxonomic groups and submerged and surface swimming. Comparative Biochemistry and Physiology Part A: Physiology, 97, 91-99.

Webb, D. C., Simonetti, P. J. \& Jones, C. P. (2001) SLOCUM: an underwater glider propelled by environmental energy. IEEE Journal of Oceanic Engineering, 26, 447-452.

Webb, P. W. (1998) Entrainment by river chub Nocomis micropogon and smallmouth bass Microterus dolomieu on cylinders. Journal of Experimental Biology, 201, 2403-2412.

Webber, D. M. \& O'dor, R. K. (1986) Monitoring the metabolic rate and activity of free-swimming squid with telemetered jet pressure. Journal of Experimental Biology, 126, 205-224.

Weihs, D. (1989) Design features and mechanics of axial locomotion in fish. American Zoology, 29, 151-160.

Williams, R. \& Noren, D. P. (2009) Swimming speed, respiration rate, and estimated cost of transport in adult killer whales. Marine Mammal Science, 25, 327-350.

Williams, T. M. (1999) The evolution of cost efficient swimming in marine mammals: limits to energetic optimization. Philosophical Transactions of the Royal Society B: Biological Sciences, 354, 193-201. 
Winberg, G. G. (Ed.) (1971) Methods for the estimation of production of aquatic animals, Academic Press.

Wolf, M. I., Licht, S. C., Hover, F. \& Triantafyllou, M. S. (2006) Open loop swimming performance of 'Finnegan' the biomimetic flapping foil AUV. In. Sixteenth (2006) International Offshore and Polar Engineering Conference, San Francisco, California, USA, May 28-June 2.

Yu, J., Hu, Y., Huo, J. \& Wang, L. (2009) Dolphin-like propulsive mechanism based on an adjustable Scotch yoke. Mechanism and Machine Theory, 44, 603-614.

Zhou, C., Wang, L., Cao, Z., Wang, S. \& Tan, M. (2007) Design and control of biomimetic robot fish FAC-1. In Kato, N. \& Kamimura, S. (Eds.) Bio-mechanisms of Swimming and Flying: Fluid Dynamics, Biomimetic Robots, and Sports Science. Tokyo, Springer. 